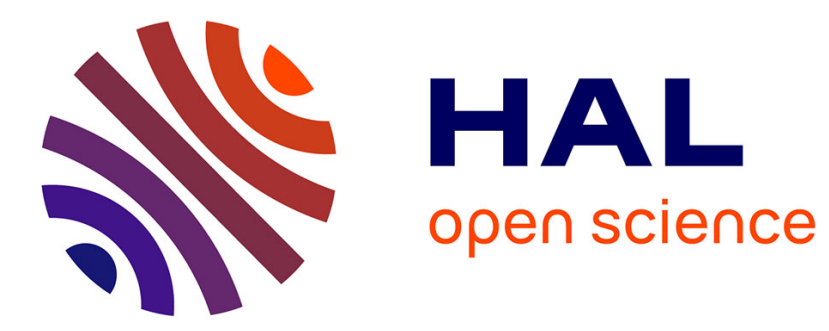

\title{
An experimental approach to nominal tense: Evidence from Pomak (Slavic)
}

Evangelia Adamou, Yair Haendler

\section{To cite this version:}

Evangelia Adamou, Yair Haendler. An experimental approach to nominal tense: Evidence from Pomak (Slavic). Language, 2020, 96 (3), pp.507-550. 10.1353/lan.2020.0040 . halshs-02508151

\section{HAL Id: halshs-02508151 https://shs.hal.science/halshs-02508151}

Submitted on 12 Oct 2020

HAL is a multi-disciplinary open access archive for the deposit and dissemination of scientific research documents, whether they are published or not. The documents may come from teaching and research institutions in France or abroad, or from public or private research centers.
L'archive ouverte pluridisciplinaire HAL, est destinée au dépôt et à la diffusion de documents scientifiques de niveau recherche, publiés ou non, émanant des établissements d'enseignement et de recherche français ou étrangers, des laboratoires publics ou privés. 


\section{YEARS}

\section{PROJECT MUSE}

An experimental approach to nominal tense: Evidence from

Pomak (Slavic)

Evangelia Adamou, Yair Haendler

Language, Volume 96, Number 3, September 2020, pp. 507-550 (Article)

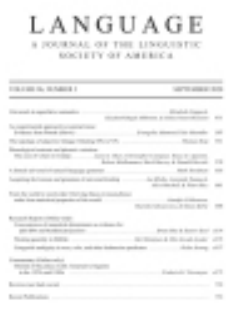

Published by Linguistic Society of America

$\Rightarrow$ For additional information about this article

https://muse.jhu.edu/article/764690 


\section{AN EXPERIMENTAL APPROACH TO NOMINAL TENSE: EVIDENCE FROM POMAK (SLAVIC)}

\author{
Evangelia AdAmou
}

\author{
French National Centre for Scientific \\ Research (CNRS), Oral Tradition \\ Languages and Civilizations (LACITO)
}

YAIR HAENDLER

Université de Paris, Laboratoire de Linguistique Formelle (LLF)

This article presents the first experimental evidence on nominal tense. Data are from Pomak, a Slavic variety that makes use of a deictic suffix for referents in the interlocutor's sphere and for past-modal reference. Forty L1-Pomak participants completed an acceptability judgment task (in Pomak) and two reaction-time experiments using auditory stimuli (in L1 Pomak and in L2 Greek). In the Pomak reaction-time experiment, in particular, participants listened to NPs with temporal reference marked either purely grammatically, with a deictic suffix, or grammatically and semantically/pragmatically. As predicted, responses were accurate and fast in grammatical-only items even though success rates improved for nominals that had additional semantic and pragmatic temporal reference. To conclude, our study confirms that Pomak deictic suffixes provide temporal information at the level of the NP and introduces a method that could be used to test the existence of nominal tense in other languages.*

Keywords: nominal tense, deixis, mental timeline, Pomak, Slavic

1. Introduction. The view whereby nouns are time-stable and nominal morphology does not encode tense is entrenched in a long philosophical tradition ${ }^{1}$ and stems from our familiarity with Indo-European languages, where verbal morphology serves to encode tense. Recently, a number of studies, conducted within both formal and functional linguistic frameworks, have challenged this view by focusing on languages in which tense is grammatically encoded in nominals, the so-called NOMINAL TENSE (Lecarme 1999, 2004, 2012, Nordlinger \& Sadler 2004). The present study contributes to this investigation by offering the first experimental evidence on nominal tense. The data are from Pomak, a nonstandardized South Slavic language spoken in Greece. In particular, we test whether nominal tense provides sufficient temporal information on its own at the level of the noun phrase (NP), that is, in the absence of concurrent linguistic means such as verbal tense and temporal adverbials. In addition, following studies on the cognitive representation of time, we explore the mental timeline(s) related to nominal tense in Pomak, where the past is associated with the interlocutor's sphere. The Pomak data therefore provide the basis for the study of a rare linguistic association of time, space, and social cognition. The remainder of the introduction is structured as follows. We start out by offering some background on nominal tense $(\S 1.1)$, followed by

\footnotetext{
* This work is supported by a public grant overseen by the French National Research Agency (ANR) as part of the program 'Investissements d'Avenir' (reference: ANR-10-LABX-0083). It contributes to the IdEx Université de Paris-ANR-18-IDEX-0001. We thank all of the participants in the study and, in particular, our research assistant for her collaboration. We are grateful to the two referees for their insightful comments. A special thank you to Language's co-editors Megan Crowhurst and John Beavers and associate editor Linda Wheeldon. We would also like to thank Eva Schultze-Berndt, Katharina Haude, Barbara Hemforth, Maïa Ponsonnet, and Stéphane Robert for their comments on earlier versions of the manuscript. Preliminary versions of this article were presented at the International Cognitive Linguistics Conference (ICLC 15), Societas Linguistica Europea (SLE 52), Société de Linguistique de Paris, and the Department of Slavistics at the University of Hokkaido, Japan. We thank members of those audiences for useful suggestions.

${ }^{1}$ For example, Aristotle defines nouns and verbs based on their temporal reference: 'By a noun (onoma) we mean a sound significant by convention, which has no reference to time ... . A verb (rhema) is that which, in addition to its proper meaning, carries with it the notion of time' (Aristotle, On interpretation; 1926 translation by E. M. Edghill).
} 
an introduction to nominal tense in Pomak (§1.2). Then, we offer an overview of the literature on space-time language and thought (§1.3). In $\S \S 2,3$, and 4 , we move on to present three experiments, before concluding with a general discussion $(\S 5)$.

1.1. BACKGROUND ON NOMINAL TENSE. The definition of nominal tense and its relation to verbal tense have been the subject of lively discussion (see Lecarme 1999, 2004, 2012, Wiltschko 2003, Nordlinger \& Sadler 2004, 2008, Matthewson 2005, Tonhauser 2007, 2008). In this article, we broadly define nominal tense as the use of 'grammatical morphology on argument nominals whose temporal interpretation is independent from the temporal interpretation of the clause' (Lecarme 2012:698). In practice, this excludes the crosslinguistically common phenomenon whereby tense, aspect, and mood (TAM) markers attach to nominals that function as predicates of a clause (Nordlinger \& Sadler 2004:777).

The use of TAM markers on argument nominals is illustrated in 1a with an example from Halkomelem (Salishan), where the past marker - $l h$ is suffixed to the noun 'grandmother', conveying the meaning 'deceased'. The same suffix -lh, when attached to the verb 'be', conveys past reference at the clausal level. ${ }^{2}$ Example $1 \mathrm{~b}$ demonstrates the temporal independence of nominal tense with respect to the clausal tense, as the past marker - $l h$ is again suffixed to the noun 'grandmother', locating the referent in the past, but the verb 'to dream about' bears the future suffix -cha, locating the reference of the clause in the future. ${ }^{3}$

(1) Halkomelem (Central Salish, Salishan [ISO code: hur])
a. Éwe-lh kw'étslexw the-l sí:lá:-lh
NEG.be-PST see DEF.F-my grandparent-PST
'He didn't see my late grandmother.'
(Nordlinger \& Sadler 2004:782, from Brent Galloway, p.c.)
b. El-éliyemet-tsel-cha the-1 sí:lá:-lh
RDP-dream.about-1sG.SBJ-FUT DEF.F-my grandparent-PST
'I'll be dreaming about my late grandmother.'
(Nordlinger \& Sadler 2004:782, from Brent Galloway, p.c.)

The independence of the temporal interpretation of nominals with respect to the temporal interpretation of the matrix-clause predicate, illustrated in 1, has also been noted in semantic theory for languages without nominal tense like English (Enç 1986, Musan 1999). For example, in the clause Diana is talked about, Diana's lifetime could be located in the past with regard to the utterance time of the predicate to be talked about (Musan 1999:655). The difference between English and Halkomelem is that only in the latter does a suffix on the noun encode overtly the temporal interpretation of the noun. This observation has led to discussions in formal linguistics on the syntactic effects of $\mathrm{T}$ (ense) features on a $\mathrm{D}$ (eterminer) and its relation to the head of a $\mathrm{T}$ (ense) $\mathrm{P}$ (hrase) (see discussion of the Halkomelem data in Wiltschko 2003 and Matthewson 2005).

\footnotetext{
${ }^{2}$ There is ongoing discussion about whether tense is verbal or nominal in this language; see, among others, Wiltschko 2003 and Matthewson 2005.

${ }^{3}$ Some authors' abbreviations have been changed in this article for glossing consistency following the Leipzig glossing rules. Abbreviations used throughout the paper are as follows: ADDR: addressee, AFFX: affix, ANIM: animate, CAUS: causative, DAT: dative, DEF: definite, DEM: demonstrative, DET: determiner, DIST: distal, DU: dual, EVID: evidential, F: feminine, FOC: focus, FUT: future, IMP: imperative, M: masculine, NEG: negation, NF: nonfeminine, NOM: nominative, NSBJ: nonsubject, PN: proper noun, PRO: pronoun, PST: past, RDP: reduplication, REFL: reflexive, REL: relativizer, REMPST: remote past, REP: reported, RESTR: restrictive, SBJ: subject, SG: singular, SPKR: speaker, TOP: topic.
} 
Unlike Halkomelem, where the same TAM markers are suffixed on nouns and on verbs, specialized nominal tense affixes are reported for Tariana, an Arawakan language (Nordlinger \& Sadler 2004, 2008, after Aikhenvald 2003). In 2a, the noun 'eagle' bears the nominal past suffix -miki, which conveys past reference at the level of the noun, whereas the suffix -pidana attaches to the verb and conveys temporal-modal reference at the level of the entire clause. In contrast, in $2 b$, the noun 'flood' receives the nominal future suffix -pena independently of the temporal reference of the suffix -pidana 'reported remote past'.

(2) Tariana (Inland Northern Arawakan, Arawakan [ISO code: tae])

a. thepi di-mare=pidana eta-miki-ri-nuku

to.water 3SG.NF-throw.CAUS=REMPST.REP eagle-PST-NF-TOP.NSBJ

'He threw the remains of the eagle (lit. the 'ex-eagle', what used to be the eagle) into water.' (Nordlinger \& Sadler 2008:326)

b. kayu-maka hĩ waripere unyane-pena di-kakwa=pidana SO-AFFX DEM:ANIM Walipere flood-FUT 3sG.NF-plan=REMPST.REP

'Thus Walipere was planning the future flood.'

(Nordlinger \& Sadler 2008:326)

In addition, a number of languages have been said to make use of TENSED ARTICLES to express temporal relationships at the level of the NP (or determiner phrase (DP), depending on theories) or of the entire clause. Tensed articles have been described, among others, in Somali, an Afro-Asiatic language (Lecarme 1999, 2004). Compare example $3 \mathrm{a}$, where the past temporal reference of the article -dii coincides with the past temporal reference of the verb, with example $3 b$, where the article -tii has a past reference independent of the clausal reference, which is anchored at the utterance time.

(3) Somali (Lowland East Cushitic, Afro-Asiatic [ISO code: som])
a. dhibaatá-dii
Khalíij-ku
wáy dhammaatay
problem-DET.F.PST Gulf-DET.M.NOM FOC.3SBJ end.PST

'The Crisis of the Gulf ended.'

b. yáa mas'úul ká ah burburín-tíi Soomaaliya

who responsible from be.RESTR destruction-DET.F.PST Somalia

'Who is responsible for the destruction of Somalia?' (Lecarme 2012:706)

Halkomelem, Tariana, and Somali are languages where nominal tense has scope over the noun, dubbed INDEPENDENT NOMINAL TAM by Nordlinger and Sadler (2004). More specifically, the independent nominal tense may have scope over the predication time (e.g. 'late grandmother', where the lifetime property of being a grandmother is located in the past, as is, through extension, the referent herself), over the time of the possessive relation (e.g. 'former house', in the sense of formerly possessed), or over the time of existence of the object or event (e.g. 'future flood') (see Tonhauser 2007, Lecarme 2012). Nordlinger and Sadler (2004) propose that in some languages nominal tense may have scope over the entire clause, that is, PROPOSITIONAL NOMINAL TAM. This may be the case in so-called TENSELESS LANGUAGES, which lack overt verbal tense and can be analyzed as also lacking TP (Wiltschko 2003). Alternatively, Lecarme (2012) suggests that nominal and clausal tense are two parallel systems.

To summarize, evidence from a variety of languages shows that nominal tense markers may convey temporal (or modal) reference on the noun and that the temporal reference of the noun may be either in agreement with or independent from clausal tense. Given that Nordlinger and Sadler (2004) define nominal tense as an inflectional category, as opposed to derivation, nominal TAM markers should be productive with a large number of nominals. For example, in English, ex-president results from a derivational 
process where the nominal prefix $e x$ - combines with a limited number of nouns. In contrast, nominal tense should be used with a variety of nouns, such as 'man', 'cat', or 'table', and not be restricted to a small set of nouns with temporal meaning, such as 'hour', 'day', or 'week'. We now turn to present nominal tense in Pomak.

1.2. Nominal tense in POMAK. The data for this study are from Pomak, a nonstandardized South Slavic language spoken in the Rhodope Mountains in Greece (see map in Figure 1). In Greece, pomatsko is the most common language name used by the speakers. The name pomakika is used in Greek by community outsiders and the authorities. In the Balkans, the language name Pomak is used to refer more broadly to the Slavic varieties traditionally spoken by Muslim communities settled in Bulgaria, Greece, and Turkey. The most common alternate names in the literature are Bulgarian, that of the most closely related standard language, or Rhodopean, a language name based on the name of the Rhodope Mountains, where Pomaks have traditionally lived. Pomak in Greece has no official status and is the language of the family and the community. It is spoken alongside the two languages used in formal education: Greek (the official language of the Greek state) and Turkish (the official language of the Muslim Minority in Greek Thrace since the Lausanne Treaty in 1923). We note that a strong shift to Turkish is currently taking place and that it has been fully completed in several localities.

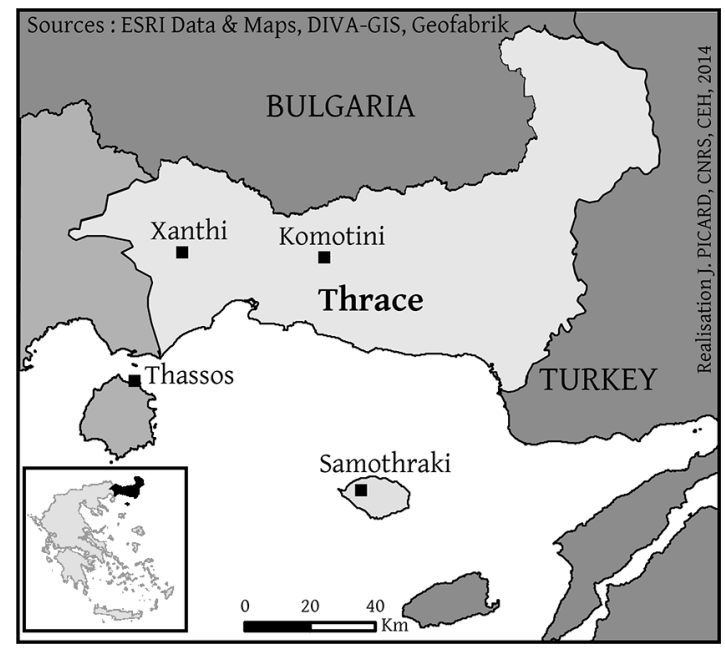

FIgURE 1. Map of the Thrace area, Greece. The study was conducted in the district of Xanthi.

In Pomak, as in any other Indo-European language, tense is expressed through verb inflection and temporal adverbs. However, Adamou (2011) has argued that, in Pomak, tense is also morphologically encoded for common nouns through a series of deictic suffixes. These deictic suffixes are used in the formation of definite articles, demonstratives, possessive pronouns, relative pronouns, and temporal subordinators. KanevskaNikolova (2006) and Fanciullo (2019) report similar uses for the Rhodope dialects of Bulgarian, where the three-way distinction is being lost under the influence of Literary Bulgarian, which makes use of a single definite article. Literary Macedonian also has three definite articles, but, unlike Pomak, these do not have any additional temporal uses.

For here-and-now situations, the three deictic suffixes are used depending on whether the referent is part of the speaker's sphere, as in 4a through the $s$-suffix form- 
ing the definite article, the interlocutor's sphere, as in $4 \mathrm{~b}$ through the $t$-suffix, or neither, as in $4 \mathrm{c}$ through the $n$-suffix. ${ }^{4}$

(4) Pomak (Slavic, Indo-European)
a. gju'zlut $\int i-s e \quad$ ['zœ-se
'nosem (ai'sa)] 'jatse sa
glasses-DEF.SPKR PRO.REL-DEF.SPKR wear.1SG now very be.3PL
'hubavi
nice

'The glasses that I'm wearing (now) are very nice!' (Adamou 2011:881)

b. gju'zlutfi-te ['zœ-te 'nosif (ai'sa)] pa'ratiki sa

glasses-DEF.ADDR PRO.REL-DEF.ADDR wear.2SG now ugly are.3PL

'The glasses that you're wearing (now) are ugly.' (Adamou 2011:881)

$\begin{array}{llll}\text { c. gju'zlutfi-ne ['zœ-ne } & \text { 'nosi] 'jatse sa 'hubavi } \\ \text { glasses-DEF.DIST PRO.REL-DEF.DIST wear.3sg very be.3PL nice }\end{array}$

'The glasses [away from both of us] that he/she is wearing are very nice.'

When the referents are located in a space and time frame distinct from the utterance situation, Adamou (2011) argues that the $t$-suffix and the $n$-suffix also serve to encode nominal tense. According to this analysis, the $t$-suffix is used when the time of the NP is located in the past with respect to the time of the utterance. In contrast, the $n$-suffix has a greater variety of uses: it serves to temporally locate the NP in the future; to indicate lack of relation between the time of the NP and the utterance situation (i.e. irrealis), typically in tales; and to contribute a habitual interpretation (in the past or future), typically when discussing traditions.

To illustrate the temporal-modal contrasts of the two deictic suffixes, let us now consider a situation where two friends are talking about different pairs of glasses. The use of the definite article would indicate uniqueness (Gundel, Hedberg, \& Zacharski 1993). The choice of the appropriate suffix would depend on nominal tense.

More specifically, to refer to the pair of glasses that the speaker was wearing last year, the definite article bearing a $t$-suffix would be appropriate, as shown in $5 \mathrm{a}$. The interpretation of the $t$-suffix, in this context, cannot be a spatial one since the glasses are not close to the interlocutor. Instead, the $t$-suffix serves to temporally locate the object 'glasses' in the past with respect to the utterance time. ${ }^{5}$ The time of the nominal coincides with the past time denoted by the verbal predicates in the relative clause and in the main clause.

In comparison, if the speaker wants to talk about the pair of glasses that she is planning to buy, then the $n$-suffix is most suited. This is illustrated in $5 \mathrm{~b}$, where the noun bears an article with the $n$-suffix, anchoring the object 'glasses' in the future with respect to the time of the utterance and coinciding with the time expressed by the future verb in the relative clause, 'will buy' (note that the relative pronoun also bears the future article). This is independent from the verb in the main clause, which anchors the predication of the clause in the utterance time. Comparison of examples $5 \mathrm{a}$ and $5 \mathrm{~b}$ therefore

\footnotetext{
${ }^{4}$ The Pomak deictic system is a PERSON-ORIENTED system, contrasting with DISTANCE-ORIENTED systems in which the deictic center is generally the speaker (Anderson \& Keenan 1985). Based on the description of spontaneous interactions, Adamou (2011) also draws attention to the fact that the choice of deictic suffixes in Pomak is not strictly determined by the spatial distance between the referent and the deictic center, that is, the speaker and the interlocutor, but can be manipulated for pragmatic reasons such as politeness.

${ }^{5}$ Note that the use of the $t$-suffix in this example does not convey any extra semantic meaning such as 'lost' or 'destroyed', as sometimes mentioned for other languages in the literature on nominal tense.
} 
illustrates the temporal contrast between the $t$-suffix and the $n$-suffix, that is, between past and future.

Moreover, if the speaker is narrating a tale, then the $n$-suffix is consistently used throughout the narration to indicate that the time of the NP has no relation to the time of the utterance, or in other words, that the glasses exist in an imaginary world; see $5 c{ }^{6}$ The use of the $n$-suffix would be independent from verbal TAM as speakers may alternate between evidential verbal morphology (to specify mediated information) and narrative present, aorist, perfect, and future to achieve various narrative effects (Adamou 2013). In this case, the contrast between the $t$ - and the $n$-suffix is one between past realis and irrealis.

(5) Pomak (Slavic, Indo-European)
a. gju'zlutfi-te ['zœ-te 'noseh (la'ni)] 'beha gu'ljami glasses-DEF.PST PRO.REL-DEF.PST wore.1sG last.year were.3PL big
'The glasses that I wore (last year) were big.'
(Adamou 2011:881)
b. gju'zlutfi-ne ['zœ-ne Se 'kupem] sa t
glasses-DEF.FUT PRO.REL-DEF.FUT will buy.1SG are.3PL red
'The glasses that I will buy are red.'
c. gju'zlutfi-ne mu 'beha/'bili
glasses-DEF.DIST DAT.3sG.M were.3PL/were.EVID.3PL big
'The glasses were big for him.' (as part of a fictional narrative)
(Adamou 2011:881)

Adamou (2011) further observes that the temporal reference of the main clause generally coincides with the temporal reference of the noun phrase, but not necessarily. To illustrate the independence of nominal tense with respect to verbal tense, Adamou (2011) provides an example with the adjective 'former', presented in 6. In this example the verb is in the future, but the article with the $t$-suffix (in the masculine singular) agrees with the lexical semantics of the adjective 'former' and locates the utterance in the past, at a time when the property 'my husband' was true of an individual (i.e. the person who was formerly my husband). Whether independent nominal tense is possible without the use of a past adjective is not discussed in that study. Our experiment 1 tackles this question.

(6) Pomak (Slavic, Indo-European)

na'prefn-et mi tfy'ljak se 'dojde 'utre

former-DEF.PST 1sG.DAT husband will come.3sG tomorrow

'My ex-husband will come tomorrow.'

(Adamou 2011:880)

The use of the $n$-suffix with future meaning independent from clausal tense is also conceivable, but is more difficult to demonstrate. As there is no adjective 'future/to be', the example in 7 illustrates this possibility with a relative clause. In this example, the relative pronoun bears the masculine definite article with the $n$-suffix and coincides with the future tense in the relative clause, while the verb in the main clause is in the past. We note, however, that in such contexts a distal interpretation is plausible (i.e. the person (away from us right now) who will marry my elder sister ... ). This makes the $n$-suffix a lesser candidate to illustrate the independence of nominal tense in Pomak.

\footnotetext{
${ }^{6}$ Adamou (2011) argues that these uses are not merely distal (i.e. an object away from us), and notes that irrealis is additionally marked in Pomak through the use of a specific temporal subordinator $a^{\prime} g a$ ' when (no anchoring in the situation of utterance)', contrasting with a'ga-no 'when (future in relation to the situation of utterance), whenever', with the neuter definite article and the $n$-suffix, and $a^{\prime} g a$-to 'when (past in relation to the situation of utterance)', with the $t$-suffix.
} 
(7) Pomak (Slavic, Indo-European)

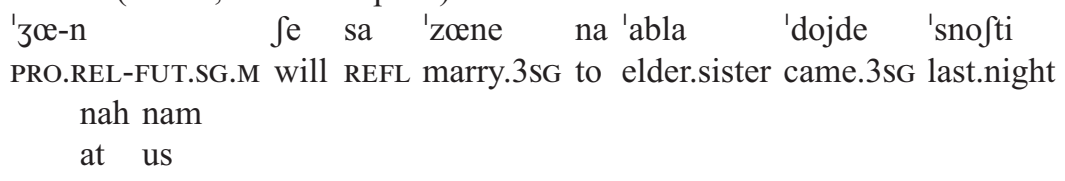

'The one who will marry my elder sister came to our home last night.'

In sum, the analysis of spontaneous and elicited data presented in Adamou 2011 shows that Pomak deictic suffixes convey temporal-modal meaning in addition to the person-oriented uses in the here and now. The most clear-cut uses of independent nominal tense are those of the $t$-suffix for past, as the $n$-suffix has a greater range of uses and is often compatible with a distal interpretation. In the present study, we want to test whether the temporal-modal reference of the Pomak deictic suffixes discussed in Adamou 2011 can be demonstrated when tested experimentally (experiments 1 and 2). In addition, we aim to investigate whether the linguistic association of a modal past with the interlocutor's sphere affects the cognitive representations of the speakers (experiments 2 and 3). To address this question, we draw on a large body of experimental evidence regarding the relation between space-time language and thought, while seeking to expand it. The next section provides an overview of the relevant literature.

1.3. Space-time language and thought. Space serves as a metaphor for the language of time (Lyons 1977, Traugott 1978, Bybee, Perkins, \& Pagliuca 1994). For example, in English the future is located in the space in front of us (e.g. the future lies ahead of us) and the past behind us (e.g. to leave the past behind). Experimental research has shown that space also serves as a metaphor to think about time (Boroditsky 2000, Casasanto \& Boroditsky 2008). In particular, researchers have identified a robust mental timeline along the left-right axis, using visual stimuli (Torralbo, Santiago, \& Lupiáñez 2006, Weger \& Pratt 2008, Fuhrman \& Boroditsky 2010) and auditory stimuli (Ulrich \& Maienborn 2010, Kong \& You 2012, Walker, Bergen, \& Núñez 2017). The mental timeline along the left-right axis is clearly not a function of language, since no known language uses left and right metaphors to talk about past and future events.

Summarizing the findings in this domain, Núñez and Cooperrider (2013) conclude that, at least in postindustrial societies, the space-time mapping along the left-right axis agrees with people's experiences in reading and writing. Indeed, it appears that individuals who have frequent and early exposure to a left-to-right writing direction associate past events with the left and future events with the right; this has been found among speakers of English (Fuhrman \& Boroditsky 2010, Walker, Bergen, \& Núñez 2017), Spanish (Ouellet et al. 2010), and German (Ulrich \& Maienborn 2010), among others. In contrast, individuals who are exposed to a right-to-left writing direction associate past events with the right and future events with the left, as in Arabic (Tversky, Kugelmass, \& Winter 1991) and Hebrew (Fuhrman \& Boroditsky 2010). This result seems to be independent from handedness, as the majority of the participants tested were right-handed.

More generally, based on a variety of findings from neuropsychological and brainimaging studies, Bueti and Walsh (2009) argue that space, time, number, and other magnitudes share common cortical metrics, which develop from action. For example, researchers report the salience of writing direction for number magnitude, whereby large numbers are associated with the right and small numbers with the left, an effect known as SPATIAL-NUMERICAL ASSOCIATION OF RESPONSE CODES, or the SNARC effect (Dehaene, Bossini, \& Giraux 1993, Zebian 2005). These studies further show that, among biliterates, the timeline based on the dominant writing system might be weakened depending on the amount of exposure to each writing system. 
Several studies indicate independent effects of attentional focus on space-time mappings. For example, Ouellet et al. (2010) show that a spatial Stroop effect is independently attested from the effects of conceptual metaphor in bimanual, speeded-response tasks. Moreover, de la Fuente et al. (2014) report that when Spanish-speaking participants wrote a text about past experience prior to a temporal mapping task, they placed the past in front of them more often than when they wrote a text about future events. A conceptualization of the past in the front space contradicts the dominant Spanish cultural mappings that locate past in the back of the body. To account for this result, the authors elaborate the TEMPORAL FOCUS HYPOTHESIS, according to which there may be variation in the mental timelines of a given population depending on their temporal focus. Similarly, Casasanto and Bottini (2014) demonstrate that mental timeline(s) can change within a short lapse of time following brief exposure to a new direction in the orthography. To accommodate these findings, Casasanto and Bottini (2014) propose the HIERARCHICAL MENTAL METAPHORS THEORY, which combines both the long-term cultural mappings and temporary changes following recent experience. These temporary mappings are presumably not entirely novel representations but universal representations that all humans share and that are subsequently narrowed down through culturalspecific experiences and linguistic categories.

More importantly for the goals of our study, Bylund and Athanasopoulos (2017) focus on the ways in which linguistic cues and language context may influence temporal processing. In their study, bilinguals modify their behavior depending on the linguistic cues available to them during the experiment, in particular when the stimuli are difficult or ambiguous. Bylund and Athanasopoulos (2017) apply the PREDICTIVE PROCESSING framework (Lupyan \& Clark 2015) to temporal cognition, and conclude that mental representations result from a combination of both top-down predictions, related to linguistic abstractions, and bottom-up processes, related to perceptual experience. According to this approach, even basic perception follows Bayesian-optimal ways of combining sensory evidence with prior beliefs and experiences. Within such probabilistic models, the brain draws as much as necessary on top-down predictions and bottomup inputs in order to minimize prediction errors.

In this article, we aim to contribute to the discussion on temporal cognition by investigating the potential cognitive effects of a little-researched linguistic phenomenon, nominal tense in Pomak, where the interlocutor's sphere is associated with the past.

2. EXPERIMENT 1. Experiment 1 is a five-point acceptability judgment task testing Pomak speakers' sensitivity to agreement between the temporal reference of a definite $\mathrm{NP}$ with the $t$-suffix (past tense) and the temporal reference of the predicate (past and future).

\subsection{Methodology.}

PARTICIPANTS. Forty L1-Pomak speakers from Greece participated in this experiment (twenty-six female; age range = fifteen to sixty years old, $M=31, S D=13.49$ ). Participants were either family members or acquaintances of the local research assistant, a nineteen-year-old female Pomak speaker. After the experimental session, participants responded to a language-background questionnaire where they listed the languages they spoke and assessed their fluency on a scale from 1 to 5 , with 5 being the highest score. Proficiency in Pomak was above 3 for all participants $(M=4.83)$. The participants gave oral consent and did not receive payment (due to a particularly sensitive political context where financial compensation for linguistic matters is stigmatized). 
STIMULI. Participants judged the acceptability of fifty-five auditorily presented sentences in total. We recorded the stimuli with the research assistant, a female Pomak native speaker who was from the same village as the participants, to make sure we did not introduce artefacts due to dialectal differences. We did not control for sentence length (hence we do not discuss response times even though they were measured by the experiment software), but we tried to ensure relative comparability by using sentences containing between five and eight words.

The experimental items included two conditions. The first condition consisted of ten sentences with $t$-suffixes forming the definite article (henceforth $t$-articles), which either agreed with the clausal tense (seven items) or were independent from it but the sentence contained a past adjective (three items). The example in 8 a illustrates a sentence with a $t$-article and past verbal tense, and example 9 shows a sentence with a $t$-article, the past adjective 'former', and future verbal tense. The second condition consisted of ten sentences where the $t$-article combined with future clausal tense, as expressed through verbal tense and temporal adverbials; an example is provided in $8 \mathrm{~b}$.

(8) Pomak (Slavic, Indo-European)

a. ja 'dadah na 'kiro 'kofta-ta faf sela'nik

1SG gave.1SG to rent house-DEF.PST in PN

'I rented the $e_{[- \text {-article }]}$ house in Salonica.' (past verb, $t$-article)

b. ?fe 'dam na 'kiro 'kofta-ta faf sela'nik za 'busene

will give.1SG to rent house-DEF.PST in PN for year

'I will rent the ${ }_{[t \text {-article] }}$ house in Salonica for the year.' (future verb, $t$-article)

(9) Pomak (Slavic, Indo-European)

na'prefn-et mi 'kopel se 'dojde 'utre

former-DEF.PST 1sG.DAT boyfriend will come.3sG tomorrow

'My ex-boyfriend ${ }_{[t \text {-article] }}$ will come tomorrow.'

(future verb, past adjective, $t$-article)

Following the experiment, however, we realized that the three sentences in condition 1 that consisted of a $t$-article and a future verb, as in 9 , were structurally similar to the ten sentences with a future verb in condition 2 , as in $8 \mathrm{~b} .{ }^{7}$ We therefore excluded those three sentences from the analysis.

We predicted that sentences in condition 1 (past-tense verb) would be rated higher than sentences in condition 2 (future-tense verb), anticipating that lack of agreement between the nominal tense and the clausal tense would render the interpretation more difficult and lead to lower ratings.

Since all sentences were plausible with respect to the life of the speaker who recorded them, and given that participants were personally familiar with the speaker, we expected the past value of the $t$-article to be triggered. Three of the sentences had two versions, one for condition 1 and one for condition 2 (as in 8), while the rest comprised different NPs and verbs.

In addition to the twenty experimental items, thirty-five filler sentences were included. The fillers comprised eighteen well-formed and seventeen ill-formed sentences. We created ungrammaticalities via violations in gender and number agreement, in tense marking, and in article usage. The resulting list had fifty-five sentences in total. Four

\footnotetext{
${ }^{7}$ The presence of the adjective was irrelevant. In fact, preliminary analysis of the results showed that the three sentences with a future-tense verb in condition 1 were rated similarly to the ten sentences with a futuretense verb in condition 2 .
} 
practice items were presented at the beginning of the task, two well-formed and two illformed, showing errors in number agreement and in preposition choice.

Procedure. This experiment, like the others presented in this article, was conducted in the area of Thrace, Greece (see Fig. 1 above). Participants responded to the experiment individually in a quiet room in their homes. Stimuli were presented on a laptop computer using Open Sesame (Mathot, Schreij, \& Theeuwes 2012). All participants listened to the sentences via headphones and responded by pressing one of five buttons on a keyboard, from 1 to 5, with 5 for the 'more natural' sentences and 1 for the 'less natural' sentences. To facilitate memorization of the scale, button 5 was marked with a happy smiley face sticker and button 1 with an unhappy smiley face sticker. When explaining the task, in Pomak, the experimenter stressed that the participant could use any number in the range between 1 and 5, and that they could take their time to think about the most appropriate rating score for each sentence.

To help ensure that participants understood the task and used the scale in similar ways, the session began with two practice sentences played by the computer that served as anchors for the highest and lowest points in the scale and on which participants received feedback from the experimenter. Once these trials were completed and the experimenter was sure that the participant understood the task, the actual experiment began. The items were presented in a fully randomized order. The experiment ended automatically once participants had responded to all fifty-five trials. The average session was less than seven minutes long, and participants generally found the task amusing and were happy to collaborate.

ANALYSIS. The data in this experiment, as well as in the other experiments presented in this article, were evaluated within a Bayesian analysis framework. Bayesian analysis consists of incorporating prior information into the data at hand, yielding a posterior probability distribution that indicates how the prior information should be updated in light of the data (Kruschke 2015, Kruschke \& Liddell 2018).

The advantages of Bayesian analysis over traditional FREQUENTIST approaches (where $t$ - or $p$-values are reported) are discussed in detail elsewhere (Wagenmakers 2007, Kruschke 2013, 2015, McElreath 2016, Nicenboim \& Vasishth 2016, Sorensen, Hohenstein, \& Vasishth 2016). Here we mention just one of the most important characteristics of Bayesian analysis, namely a straightforward interpretation of the results. The posterior distribution of a main effect or an interaction provides information on how reliable the evidence for the effect or interaction is, given the data at hand. This contrasts with frequentist null-hypothesis significance testing, which provides information on the null hypothesis (i.e. the possibility that there is no effect), thus not on the hypothesis actually being tested by the experimenter (Vasishth \& Nicenboim 2016). Moreover, uncertainty around effects is expressed in a Bayesian framework by means of credible intervals. For example, the $95 \%$ credible intervals of a posterior distribution mark the area of the distribution within which one can be sure with a probability of 0.95 that the true value of the parameter lies. Bayesian credible intervals thus provide direct information on the results. In contrast, frequentist confidence intervals provide information on the likelihood of obtaining an interval containing the true value of the parameter, assuming repeated sampling of the data (Wagenmakers 2007, Hoekstra et al. 2014, Morey et al. 2016, Nicenboim \& Vasishth 2016, Vasishth \& Nicenboim 2016).

The acceptability judgment data were analyzed with a cumulative mixed-effects model with a logit link function. This model (also known as proportional-odds model: McCullagh 1980, Agresti 2010, Christensen \& Brockhoff 2013) measures the likeli- 
hood of a response being in a given category or below it, versus the likelihood of the response being in a higher category. If there are five points on the response scale, then the model evaluates the overall change in response from one category to the next (from rating category 1 to 2 , from 2 to 3 , and so on), expressed by four intercepts. By including the same fixed- and random-effects structure for each evaluation of the change in response category (that is, for each logit equation in the model), the parameters can be interpreted in terms of main effects and interactions, similarly to linear regression techniques. The advantage of the cumulative logit model is that it accounts for the ordinal nature of the acceptability scale. The model was fitted using the 'brms' package (Bürkner 2017, 2018) in R (R Core Team 2018).

The factor VERBAL TENSE was coded as 1 (past) and -1 (future). The fixed-effects part included an intercept parameter and a slope parameter of Verbal tense. The random-effects part included an adjustment for participants of an intercept and a slope of the main effect of Verbal tense, as well as the correlation between intercept and slope, and an adjustment for items of an intercept only (since Verbal tense was not a withinitem variable). For all model parameters we defined weakly informative priors (Sorensen et al. 2016). The fixed- and random-effects intercepts and slopes were assigned a student's $t$-distribution $(d f=3, \mathrm{mu}=0$, sigma $=10)$, and the random-effects correlations were assigned an LKJ-correlation prior $(z e t a=2)($ Lewandowski, Kurowicka, \& Joe 2009, Sorensen et al. 2016). The model was run with four Markov chains, including 6,000 iterations per chain, of which the first half, the so-called warm-up phase, was discarded. Chain convergence was verified visually. In addition, we checked that the $\hat{R}$ statistics for all model parameters were equal to 1 and that the number of effective samples per iteration was reasonably high (Gelman et al. 2014).

The Bayesian model generated a posterior distribution for each of the model parameters. The parameters of interest are typically the slopes of the population-level (or fixed) effects. In this model, it is the slope parameter for the fixed effect of Verbal tense. Since the factor levels were coded as 1 and -1, zero represents the point of "no difference' between the two types of verbal tense (past and future). We therefore calculate the probability that the parameter of interest is greater or smaller than zero. A high probability that the parameter for the main effect of Verbal tense is greater than zero would suggest there is evidence that past tense (coded as 1) is rated higher than future tense (coded as -1). By contrast, high probability that the parameter is less than zero would mean that future tense is rated higher than past tense.

For the statistical inference we show the range and the estimated mean $(\hat{\beta})$ of the posterior distribution for the parameter of interest, as well as the $95 \%$ credible intervals. Moreover, we calculate the probability that the posterior distribution for the parameter of interest is less or greater than zero (depending on the direction of the effect). It should be emphasized that, in this kind of analysis, we do not describe the results in terms of 'significant' or 'nonsignificant' effects. These terms, used in frequentist analyses, reflect the binary nature of statistical inference (an effect can be either significant or not). By contrast, inference in the Bayesian analysis used here is not categorical. Evidence for a particular effect may be more or less strong, as expressed by how the posterior is located with respect to the zero point.

2.2. RESUlTS. First, to make sure participants performed the task according to our expectations, we checked the mean rating on the filler sentences. The well-formed fillers were rated with an average of 4.3 , and the ill-formed ones were rated with an average of 2.2, confirming that participants understood the task and performed it properly. Next, we checked the average rating for the sentences with the $t$-article. As can be seen in Fig- 
ure 2, sentences with a past-tense verb were rated higher (4.3) than sentences with a future-tense verb (3.5).

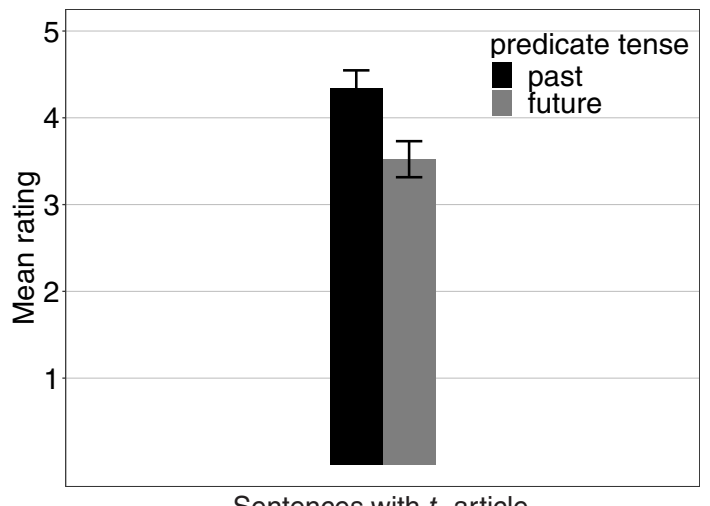

FIGURE 2. Mean acceptability rating of $t$-article sentences in the acceptability judgment task. The left (black) bar marks sentences with past predicate tense (compatible with the $t$-article past temporal interpretation), and the right (gray) bar sentences with future predicate tense (incompatible with the $t$-article past temporal interpretation). The error bars represent $95 \%$ confidence intervals.

The Bayesian model shows that most of the posterior distribution for the fixed main effect of Verbal tense (mean $\hat{\beta}=0.60$ ) lies in the range of positive numbers (greater than zero). This means that sentences with past verbal tense were rated higher than sentences with future verbal tense. As can be seen in Figure 3, zero is located outside the 95\% credible intervals $(95 \% \mathrm{CrI}=[0.01,1.19])$. The probability of the posterior being in the range of positive numbers is 0.98 , suggesting strong evidence for the effect of Verbal tense in the predicted direction.

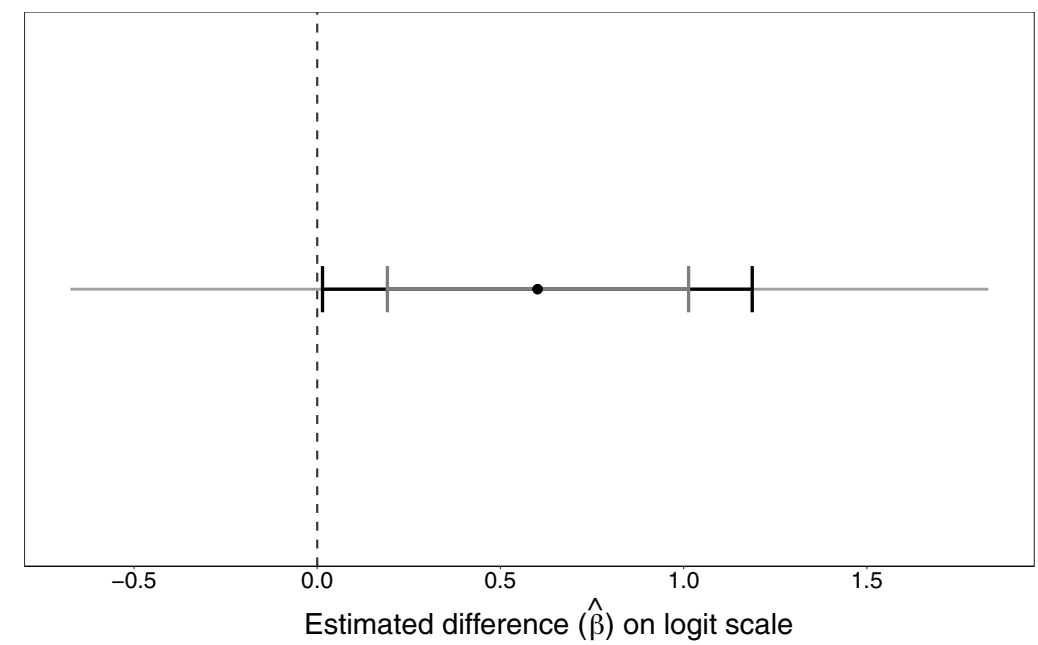

FIGURE 3. Posterior distribution for the main fixed effect of Verbal tense in the model on the acceptability rating data. The black dot marks the posterior mean; the outer bars mark the $95 \%$ credible intervals, within which $95 \%$ of the distribution lies; the inner bars mark the $85 \%$ credible intervals; zero is marked with a vertical dashed line. 
2.3. Discussion. The results show a clear effect in the predicted direction, with two levels of acceptability for the experimental sentences. ${ }^{8}$ More specifically, participants gave a higher rating score to the sentences comprising NPs with $t$-articles that agreed with the past tense of the predicate than to those comprising NPs with $t$-articles that did not agree with the future tense of the predicate. The difference in ratings helps refine the claims in Adamou 2011. On the one hand, it shows that past temporal meaning at the level of the NP is less acceptable when there is no agreement with the clausal tense. On the other hand, it reveals that sentences with no such agreement are nonetheless acceptable, as they were rated higher than the ill-formed filler sentences that had violations in gender and number agreement. We can interpret this result as evidence that comprehenders opted for an independent past interpretation of the nominal argument in the sentences where there was no agreement between the nominal tense and the clausal tense. Although we did not test the precise contribution of a temporal adjective, our results suggest that it is not required for an independent reading of nominal past tense.

In sum, this experiment shows that Pomak speakers are sensitive to agreement between the nominal past tense of the $t$-article and the temporal reference of the predicate. The next experiment assessed whether the temporal reference of the deictic suffixes may be entirely independent from the temporal reference of a verb or an adverb.

3. EXPERIMENT 2. In the second experiment participants listened to NPs with temporal reference marked either purely grammatically, with a deictic suffix, or grammatically and semantically/pragmatically. Participants had to identify the items as referring either to the past or to the future by pressing buttons located to their left and right sides. We also tested the association of the past with the interlocutor's sphere. To this end, we manipulated the experimenter's location with respect to the buttons corresponding to the past and the future.

This experiment was designed to address two research questions. First, do definite articles in Pomak carry temporal information on their own, independent of other linguistic means (verbal or adverbial)? Following Adamou 2011, we predict that Pomak NPs with definite articles will provide sufficient temporal information. More generally, following the literature on the independence of nominal tense (e.g. Nordlinger \& Sadler 2004, Lecarme 2012), we predict that nominal tense should allow participants to decide on the temporal reference of an NP.

Second, do Pomak definite articles mediate the conceptualization of time along the left-right axis? In particular, is past-modal reference, as expressed through the $t$-article, associated with the experimenter's sphere? If the mental timeline along the left-right axis follows reading habits (e.g. Fuhrman \& Boroditsky 2010), then the location of the experimenter should combine with this effect (Bylund \& Athanasopoulos 2017). We predict, in particular, that the experimenter's position near the past button, whether on the left or on the right, should facilitate responses.

\subsection{Methodology.}

PARTICIPANTS. Forty L1-Pomak speakers from Greece participated in this experiment (twenty-three female; age range = sixteen to fifty years old, $M=30, S D=8.63$ ). Half of the participants were the same as in experiment 1 . All were family members or acquaintances of the Pomak research assistant. Participants responded to a language-

\footnotetext{
${ }^{8}$ As Gibson, Piantadosi, and Fedorenko (2013:235) note: 'When performing quantitative experiments, one quickly discovers that syntactic acceptability appears fine-grained and largely continuous'.
} 
background questionnaire after the experimental session. All participants but one rated their proficiency in Pomak as 5 (on a scale from 1 to 5). All reported speaking Greek fluently $(M=4.33)$, and most of them also spoke Turkish, although less fluently $(M=2.55)$. Participants had no formal education in Pomak as there is no Pomak curriculum available in Greece, but some said that they text in Pomak using the Latin script. Eight participants had attended at most primary school, twelve secondary school, and twenty university. Participants also reported reading the Koran in Arabic and in Arabic script, that is, from right to left, although they said they do not speak, read, or write in Arabic otherwise. Generally they started to read the Koran at age six at Koranic school, the same time at which they attended primary school. But occasional exposure prior to this age within the family circle was also reported. Some participants reported reading the Koran on special occasions, like holidays, and others reading it at least once per week. Since the participants are familiar with both left-to-right and right-to-left writing systems, we refrain from making any predictions about the congruence between the tense of the references (past/future) and the side of the past button (left/right).

Design. The experimental design was inspired by a bimanual response task elaborated by Walker, Bergen, and Núñez (2017). The original experiment tested the frontback and the left-right axis among English speakers in the US. Participants read stimuli consisting of forty typical life events (NPs: e.g. your college graduation, adverbials: e.g. yesterday, or verbal phrases using gerunds: e.g. getting your driver's permit). They had to indicate with a mouse click whether the event had taken place in the past of their own lives or was likely to occur in the future (deictic judgment condition) or whether a given event took place before or after another event (sequence judgment condition).

In the present experiment, in which only the deictic judgment condition was retained, we used auditory rather than written stimuli, given that Pomak is a nonstandard variety that is written only in informal communication. Participants made temporal judgments that were related to the life of the experimenter rather than their own life, to increase the relevance of the interlocutor in the responses. To investigate nominal tense, the stimuli in our study consisted of NPs involving a deictic suffix, for example, 'the ${ }_{[n \text {-article }]}$ wedding'. We tested only the left-right axis, which allows participants to see the experimenter. We added a manipulation to explore the effects of the experimenter's location with respect to the left or right key.

STIMULI. Forty auditory stimuli were recorded by the research assistant, an eighteenyear-old female Pomak speaker who was about to start her first year at university at the moment of the study. Twenty stimuli corresponded to referents in the experimenter's past (e.g. 'the baby teeth'), and twenty stimuli corresponded to referents that were likely to occur in the experimenter's future life (e.g. 'the wedding').

Ten NPs could be identified as belonging to the past or future with the help of the grammatical marker as well as semantic and pragmatic cues, for example, 'the baby teeth' for past or 'the wedding' for future. By contrast, the other ten items could be recognized as belonging to the past or future only by means of the grammatical marker, for example, 'the friends' with the $t$-article, with the intended meaning 'the ex-friends', versus 'the friends' with the $n$-article, with the intended meaning 'the future friends' (see Table 1). The first-person possessive pronoun 'my', referring to the experimenter, was used whenever possible, but generally it was more natural for past than for future referents. We tested both relational nouns, like 'boyfriend' and 'teeth', and nonrelational nouns, like 'dress', for which the possessive relation is not linked to the lexical meaning of the noun, but can shift to being relational in favor of the possessor depend- 
ing on the pragmatic context (Vikner \& Jensen 2002). Most nouns were singular, referring to a unique object, but some plurals were also used, referring to a maximal set of objects, either with a definite article or a possessive pronoun and a definite article. Articles inflect for gender and number. We note that the locus of the articles in possessive noun phrases is on the possessive rather than on the head nominal, with the exception of the short form of the possessive pronoun that follows the definite noun.

We also note that the articles could be interpreted in relation to the here and now, either as distal (associated to the $n$-article) or as close to the interlocutor (associated to the $t$-article). However, we expected that the forced binary choice between past and future would guide participants toward a temporal interpretation throughout the entire experiment.

STRICTLY GRAMMATICAL

Past

$\begin{array}{ll}\text { moj-et telifon } & \text { 'my (past) telephone' } \\ \text { moj-et metfit } & \text { 'my (past) school' } \\ \text { moj-et ders } & \text { 'my (past) class' } \\ \text { moj-tu kutfe } & \text { 'my (past) dog' } \\ \text { moj-ta udayo } & \text { 'my (past) room' } \\ \text { moj-et kopel } & \text { 'my (past) boyfriend' } \\ \text { moj-et guzyk } & \text { 'my (past) coat' } \\ \text { moj-et fustan } & \text { 'my (past) dress' } \\ \text { moj-ta tfanta } & \text { 'my (past) bag' } \\ \text { arkadaje-te } & \text { 'the (past) friends' }\end{array}$

\section{Future}

moj-nu kut $\int \quad$ 'my (future) dog'

moj-ne dersve 'my (future) classes'

arkadafe-ne

met $\int i t-e n$

moj-ne dykjan

moj-na kuliba

mutor-an

tumafil-en

nova-na kofta

kismet-en mi

GRAMMATICAL, SEMANTIC, AND PRAGMATIC

$$
\begin{aligned}
& \text { moj-et be } \int i k \\
& \text { moj-et verespit } \\
& \text { moj-ta lulka } \\
& \text { moj-ta kukla } \\
& \text { moj-et jurgan } \\
& \text { moj-ta } \int 1 \text { e } \\
& \text { moj-tu kuritu } \\
& \text { porvi-te zobi } \\
& \text { daskalitsa-ta } \\
& \text { doln-et met } \text { jit }
\end{aligned}
$$

\author{
'my (past) baby bed' \\ 'my (past) bicycle' \\ 'my (past) cradle' \\ 'my (past) doll' \\ 'my (past) baby sleeping bag' \\ 'my (past) baby bottle' \\ 'my (past) baby bath' \\ 'the (past) baby teeth' \\ 'the (past) schoolteacher' \\ 'the (past) Koran school'
}

TABLE 1. Stimuli used in experiment 2 (forty noun phrases, of which twenty related to past referents and twenty to future referents).

Procedure. Participants were tested individually at their homes in a calm environment in the presence of the experimenter. The experimenter was the same person who recorded the stimuli and to whose life the stimuli referred. She was either a family member or a peer of the participants. Participants were seated in front of a laptop, approximately $60 \mathrm{~cm}$ from a fourteen-inch screen, and listened to the auditory stimuli using headphones. The experimenter gave the instructions in Pomak prior to the experiment. Participants were instructed to respond by pressing a key located to their left or right when identifying an item as referring either to the experimenter's past (naprefn-et 'past/ahead-past.article') or to her future (kana-nu fe stane 'when-future.article will happen'). In some trials, the left key corresponded to the past and the right key to the future, and in other trials it was the opposite. The experimenter did not use any gestures or expressions involving the right or left. Following Walker, Bergen, and Núñez (2017), the buttons to be pressed were color-coded, and participants were instructed at the beginning of each block whether they had to press the white key (on the left) for past referents and the pink key (on the right) for future referents, or vice versa. Similar to the 
original study, color-coding was not counterbalanced, as it was not expected to have an effect on the results. Throughout the task, accuracy and reaction times were measured. There were no time restrictions, but participants were told that both accuracy and speed were important. They were allowed to take short breaks between blocks and interact with the experimenter. The entire session lasted on average ten to fifteen minutes.

As in Walker, Bergen, \& Núñez 2017, each participant completed four blocks. Each block consisted of four practice trials and forty experimental trials, which were fully randomized (see Table 1 for the list of the experimental items). In total, each participant completed 160 experimental trials (4 blocks $\times 40$ stimuli). In blocks 1 and 3, the button for the past was located to the left of the participants and the button for the future was located to their right. In blocks 2 and 4 the location was reversed: the past button was located to the right and the future button was located to the left (see Figure 4).

\begin{tabular}{|c|c|c|c|c|}
\hline & \multicolumn{2}{|c|}{ Subjects $1-20$} & \multicolumn{2}{|c|}{ Subjects $21-40$} \\
\hline \multirow{2}{*}{ Block 1} & Past & \begin{tabular}{|l|} 
Future \\
\end{tabular} & \begin{tabular}{|l|} 
Past \\
\end{tabular} & \begin{tabular}{|l|} 
Future \\
\end{tabular} \\
\hline & Experimenter & & & Experimenter \\
\hline \multirow{2}{*}{ Block 2 } & \begin{tabular}{|l|} 
Future \\
\end{tabular} & Past & Future & Past \\
\hline & Experimenter & & & Experimenter \\
\hline \multirow{2}{*}{\begin{tabular}{|l|} 
Block 3 \\
\end{tabular}} & Past & Future & Past & Future \\
\hline & & Experimenter & Experimenter & \\
\hline \multirow{2}{*}{\begin{tabular}{|l|} 
Block 4 \\
\end{tabular}} & Future & Past & Future & Past \\
\hline & & Experimenter & Experimenter & \\
\hline
\end{tabular}

FIgURE 4. A diagram of the setup in the Pomak experiment. In blocks 1 and 3, the past button was located on the left side and the future button on the right side. In blocks 2 and 4, it was the opposite. For half of the participants, the experimenter sat on the left side for two blocks and then moved to the right side for the remaining part of the experiment. For the other half, the experimenter started on the right side for two blocks and then moved to the left side.

Testing the impact of the association between 'interlocutor position' and 'past' is methodologically challenging. There is a qualitative difference between a situation where someone interacts with an interlocutor and one where the interlocutor is an observer during the experiment, even though she is the interlocutor during the experimental session and stimuli are related to her life. In an attempt to explore the impact of the experimenter's position, half of the participants started out with the experimenter sitting to their left for two blocks, whereas in the following two blocks the experimenter sat to their right. For the other half of the participants, the experimenter first sat to their right for two blocks and then to their left for the following two blocks. The experimenter changed sides only once during the experiment in order to make the change look as natural as possible. When asked why she was doing so, the experimenter replied that she was not comfortable sitting on the other side (see Fig. 4). During the trials, the experimenter had a passive stance. ${ }^{9}$

\footnotetext{
${ }^{9}$ If we had fully counterbalanced both the past button position and the experimenter's position, we would have ended up with the experimenter having to change position more than once throughout the session. Although this would have had an advantage in terms of experimental design, it would have made the experimental setting and the role of the experimenter in it too unnatural.
} 
Participants were asked to fixate a cross in the middle of the computer screen while responding to the experiment, but our experiment did not include visual stimuli so there is no guarantee that they did not shift their attention during the experiment to another point, such as the keyboard. In either case, the experimenter would have been located outside of the participant's attention window, about $40^{\circ}$ along the horizontal meridian (Hüttermann, Noël, \& Memmert 2017), but within the participant's visual field, which is five to six times bigger than the attention window (Hüttermann \& Memmert 2017). We avoided dead angles by keeping a distance of approximately $60 \mathrm{~cm}$ between the participant and the experimenter. The participants were not informed about the goal of the experiment. At the end of each block, they were given feedback through the Open Sesame software about their success rate in the block.

ANALYSIS. For the analysis of the accuracy data, correct button presses (that is, pressing the key corresponding to the temporal reference conveyed by the presented item) were coded as 1 and incorrect ones as 0 . These data were analyzed with a Bayesian mixedeffects model that assumes a Bernoulli distribution of the binary dependent variable. The reaction times were analyzed with a Bayesian mixed-effects model that assumes a shifted log-normal distribution of the dependent variable. The log-transformation is performed to achieve a normal distribution of the reaction times, which are typically right-skewed. Moreover, the distribution of the modeled reaction times is shifted because they can only be positive (Nicenboim et al. 2018). All models were fitted with the 'brms' package in R. The data from all of the experiments presented in this article, as well as the scripts used for the analyses, can be accessed at https://osf.io/kbzmv/.

The Bernoulli and shifted log-normal models had similar structures. The experimental factors we included were those of PAST BUTTON POSITION (to the left or right of the participant), EXPERIMENTER POSITION (near the past or the future button), TENSE (past or future reference of the item), and MARKER (grammatical-only or grammatical-andpragmatic). In the fixed-effects part, we estimated parameters for an intercept, all of the main effects of these four factors, and all of their possible interactions. In the random effects adjusted for participants, we estimated parameters for intercepts, slopes for the four main effects and for all possible interactions, and the correlations between intercepts and slopes. In the random effects adjusted for items, we estimated parameters for intercepts; slopes for the main effect of Past button position, Experimenter position, and their interaction; and the correlations between intercepts and slopes (the other two factors were between-item variables, hence were not included in the random-effects part for items).

We also ran two additional models, one for the accuracy data and one for the reaction-time data, where we replaced Past button position with the factor EXPERIMENT HALF (second vs. first half). The difference is that for the former factor, blocks 1 and 3 are merged (past button on the left) and blocks 2 and 4 are merged (past button on the right). But this factor is confounded with the fact that the past button is always on the right in a later block in the course of the experimental session, as compared to the blocks where the past button is on the left. In the Experiment half factor, blocks 1 and 2 are merged to form the first half and blocks 3 and 4 are merged to form the second half. Thus, any effect of this factor would reflect a change in the performance pattern that is due to the chronological order of the blocks (note that we cannot include the four blocks separately as a factor, since there is a nonlinearity in the data that is not captured by the models we use).

All of the variables in the models were centered around zero in the following manner: the factor Past button position was coded as 1 (left) and -1 (right), Experimenter position 
was coded as 1 (near the past button) and -1 (near the future button), Tense was coded as 1 (future) and -1 (past), Marker was coded as 1 (grammatical-only) and -1 (grammatical-and-pragmatic), and Experiment half was coded as 1 (second half) and -1 (first half). All model parameters were assigned weakly informative priors. In the Bernoulli model, the fixed-effects parameters were assigned a normal distribution as prior with mean 0 and standard deviation 10 (on logit scale), the random-effects parameters were assigned a normal distribution with mean 0 and standard deviation 1 , and the random correlation parameters were assigned an LKJ-correlation prior with zeta $=2$. In the shifted log-normal model, the fixed-effects parameters, the error sigma parameter, the shift parameter, and the random-effects parameters were all assigned a normal distribution with mean 0 and standard deviation 1 (on log scale), whereas the random correlation parameters were assigned an LKJ prior with zeta $=2$. Each model was run with four Markov chains, including 3,000 iterations per chain (sometimes increased to 6,000 iterations, if the effective sample size was too low), of which the first half was discarded. We visually verified chain convergence, and checked that the $\hat{R}$ statistics for all model parameters were equal to 1 and that the numbers of effective samples per iteration were reasonably high.

3.2. Results. Prior to the analysis, we looked at each item individually, checking for patterns in accuracy or in reaction times that were markedly different from the rest of the items. In the accuracy data, one item (mojet befik 'my (past) baby bed') had an extremely low rate in two of the four conditions (mean proportion of accuracy: 0.15 and 0.05 ), as compared to the average rate of the remaining items (about 0.8). We therefore excluded this item from the analysis in this experiment. For the reaction-time data analysis, we followed a common procedure of excluding response times that were two standard deviations faster or slower as compared to the overall group's performance across conditions. This resulted in the exclusion of about $4 \%$ of the data in the reactiontime analysis. The appendix lists all of the items in the Pomak experiment along with their mean proportion of accuracy and mean reaction times.

ACCURACY. Overall, the accuracy rate on average was above $80 \%$. This indicates that participants understood the task and that the temporal information provided by the deictic suffixes was sufficiently clear to guide them toward the correct answer. As can be seen in Figure 5, which shows the accuracy data in the various experimental conditions, participants pressed the correct button less often when both the past-corresponding button and the experimenter were located to their left than when the experimenter was next to the future button on their right side. No such effect of experimenter location emerged when the past button was on the right side of the participants. Also, the same pattern emerges in past- and future-tense trials. As shown in Figure 6, the model for the accuracy data indicates that there is strong evidence for the interaction of Past button position by Experimenter position, where zero is excluded from the $95 \%$ credible intervals of the posterior (estimated posterior mean $=-0.27 ; 95 \% \mathrm{CrI}=[-0.54,-0.01]$; probability that the posterior is less than zero $=0.98$ ). There was also evidence for the main effect of Marker (estimated posterior mean $=-0.24 ; 95 \% \mathrm{CrI}=[-0.43,-0.05]$; probability that the posterior is less than zero $=0.99$ ). This effect means that participants were more accurate when temporal reference was inferable using both the grammatical marker and pragmatics, as compared to when temporal reference was inferable only through the grammatical marker. There was little to no evidence for the other fixed effects, since zero was included in the $95 \%$ credible intervals of their posteriors.

REACTION TIMES. For the analysis of the reaction times we kept only the trials with correct button presses. Here, Experimenter position did not have any effect. The only effect for which we found evidence is the main effect of Past button position. When the 


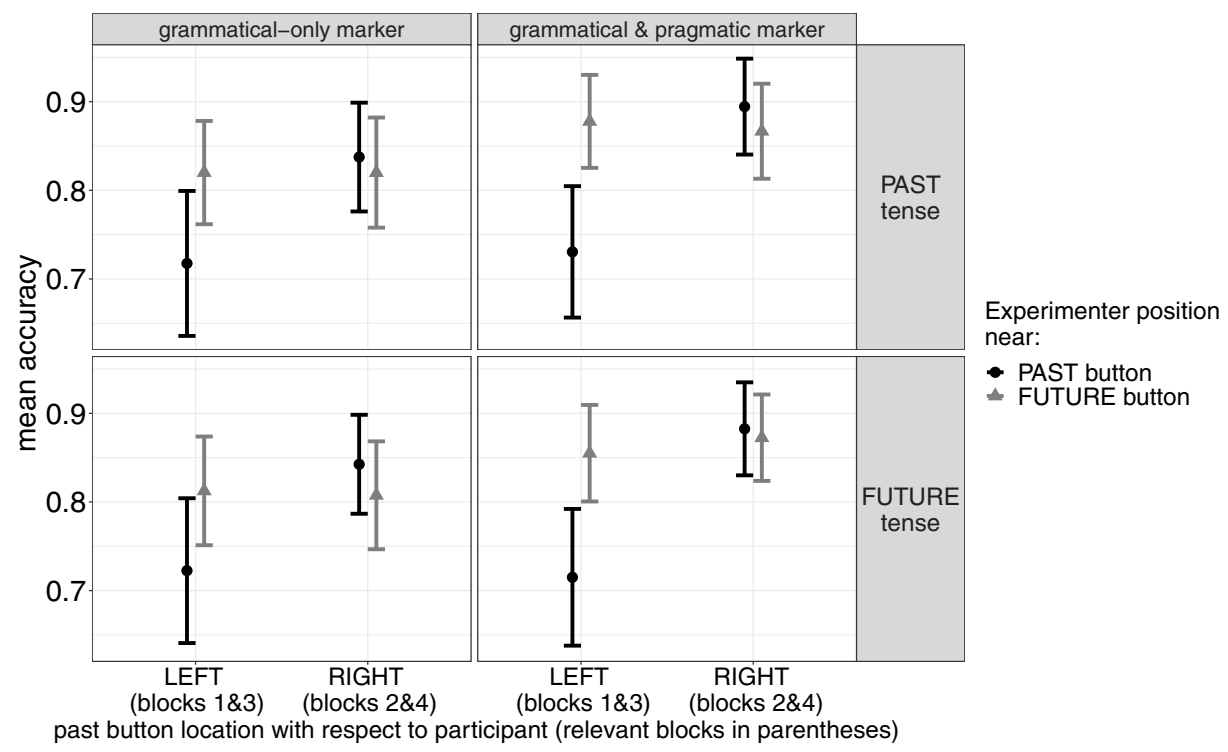

Figure 5. Mean accuracy rate (with 95\% confidence intervals) in experiment 2 (Pomak) in relation to the various experimental manipulations: the location of the past-corresponding button with respect to participants (x-axis); NPs where temporal reference is marked only grammatically (left panels) or grammatically and pragmatically (right panels); NPs in the past tense (top panels) or future tense (bottom panels). Black circles stand for trials in which the experimenter was located next to the past-corresponding button; gray triangles stand for trials in which the experimenter was located next to the future-corresponding button.

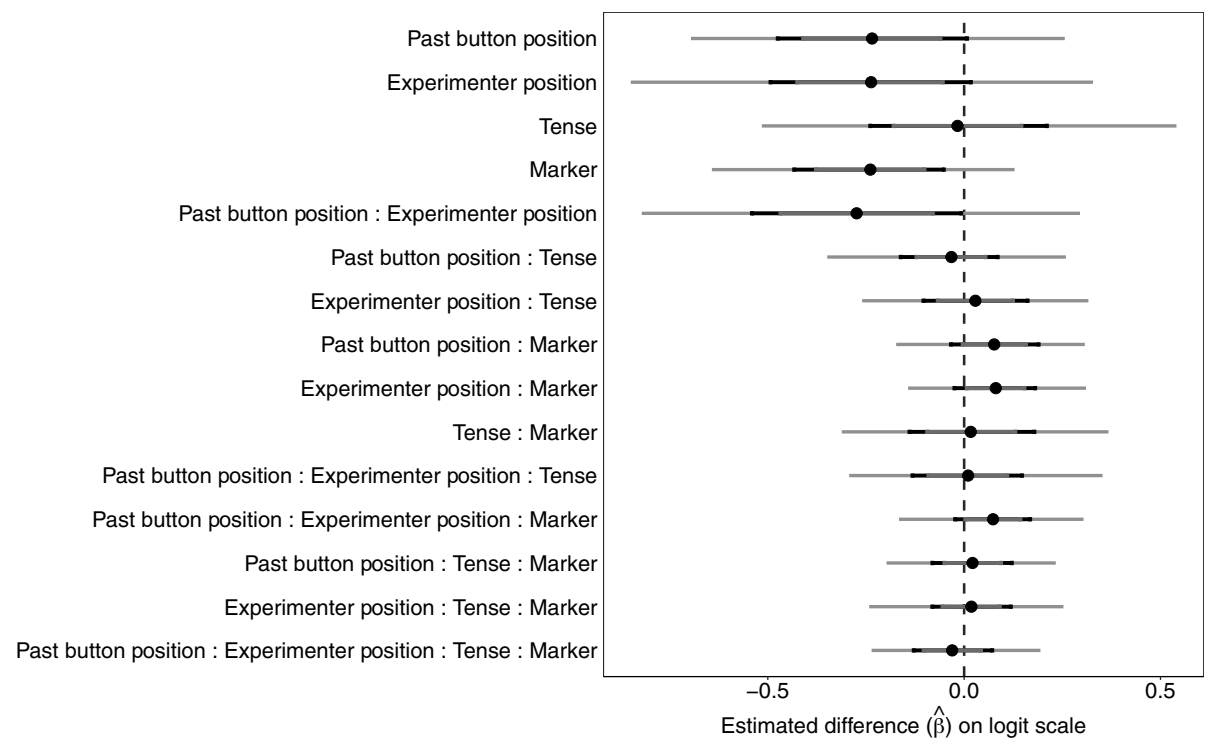

FIgURE 6. Accuracy data in experiment 2 (Pomak): posterior distributions for the fixed effects. The black dot marks the posterior mean; the outer bars mark the $95 \%$ credible intervals; the inner bars mark the $85 \%$ credible intervals; zero is marked with a vertical dashed line.

button corresponding to the past was located to the left of the participants, they took longer to press it than when it was located on their right side (Figure 7). The posterior distribution sampled for this effect had a range of positive numbers only (estimated posterior mean $=0.05 ; 95 \% \mathrm{CrI}=[0.03,0.07])$, and the probability that this posterior is less 
than zero was close to 0 . In other words, it is very unlikely that the true value of this parameter is negative (Figure 8). There was no evidence for the other fixed-effects model terms, for all of which zero was included in the $95 \%$ credible intervals.

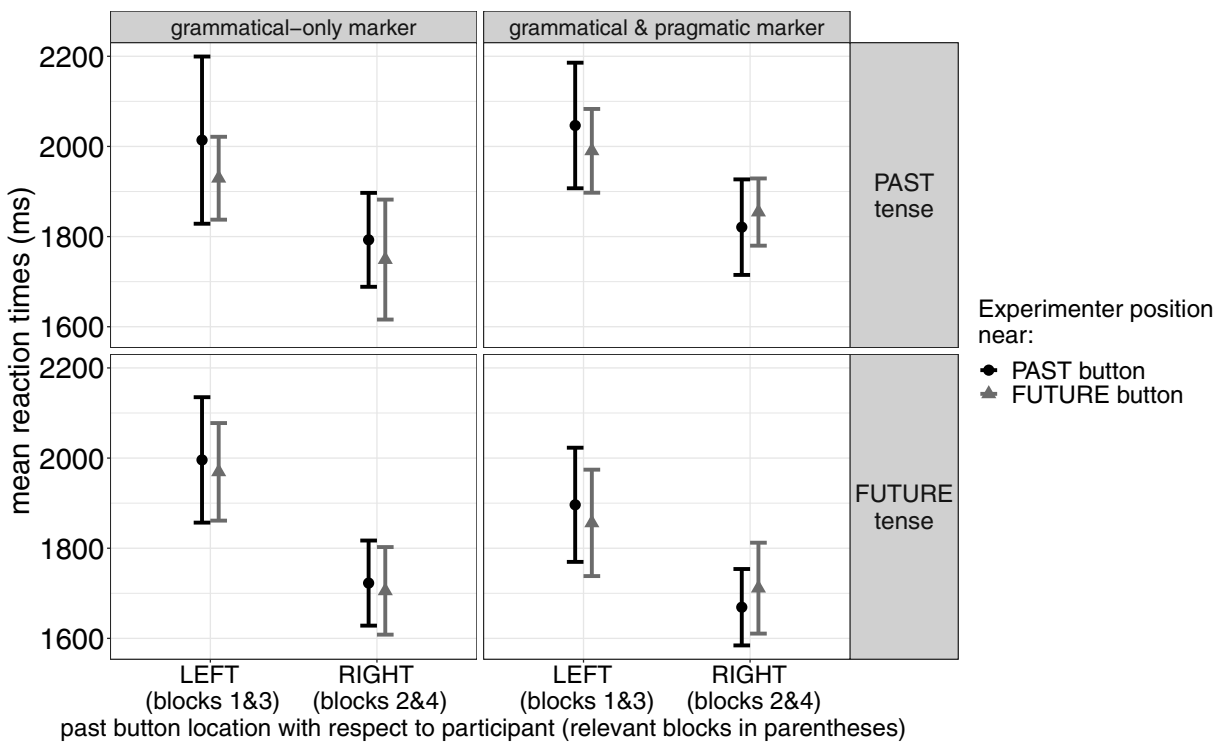

FIGURE 7. Mean reaction times in milliseconds (with 95\% confidence intervals) in experiment 2 (Pomak) in relation to the various experimental manipulations: the location of the past-corresponding button with respect to participants (x-axis); NPs where temporal reference is marked only grammatically (left panels) or grammatically and pragmatically (right panels); NPs in the past tense (top panels) or future tense (bottom panels). Black circles stand for trials in which the experimenter was located next to the past-corresponding button; gray triangles stand for trials in which the experimenter was located next to the future-corresponding button.

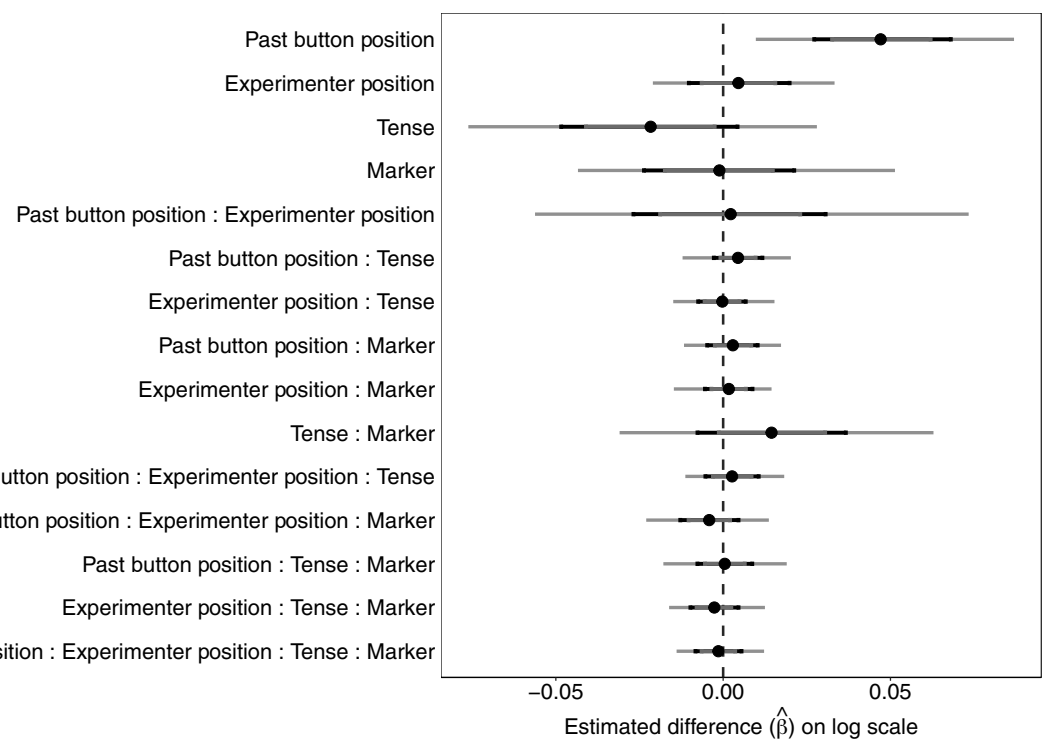

FIGURE 8. Reaction times in experiment 2 (Pomak): posterior distributions for the fixed effects. The black dot marks the posterior mean; the outer bars mark the $95 \%$ credible intervals; the inner bars mark the $85 \%$ credible intervals; zero is marked with a vertical dashed line. 
In the next step of the analysis, we replaced the factor Past button position with the variable Experiment half.

ACCURACY (with the variable Experiment half). The accuracy data are shown in Figure 9, with the posteriors in Figure 10. The reaction-time data are shown in Figure 11 and the posteriors in Figure 12. The only effect for which there is evidence in the accuracy data analysis is the main effect of Marker (estimated posterior mean $=-0.22 ; 95 \%$ $\mathrm{CrI}=[-0.42,-0.04]$; probability that the posterior is less than zero $=0.99)$, which, as before, indicates participants' higher accuracy rate when the temporal reference of the nominal was inferable both grammatically and pragmatically.

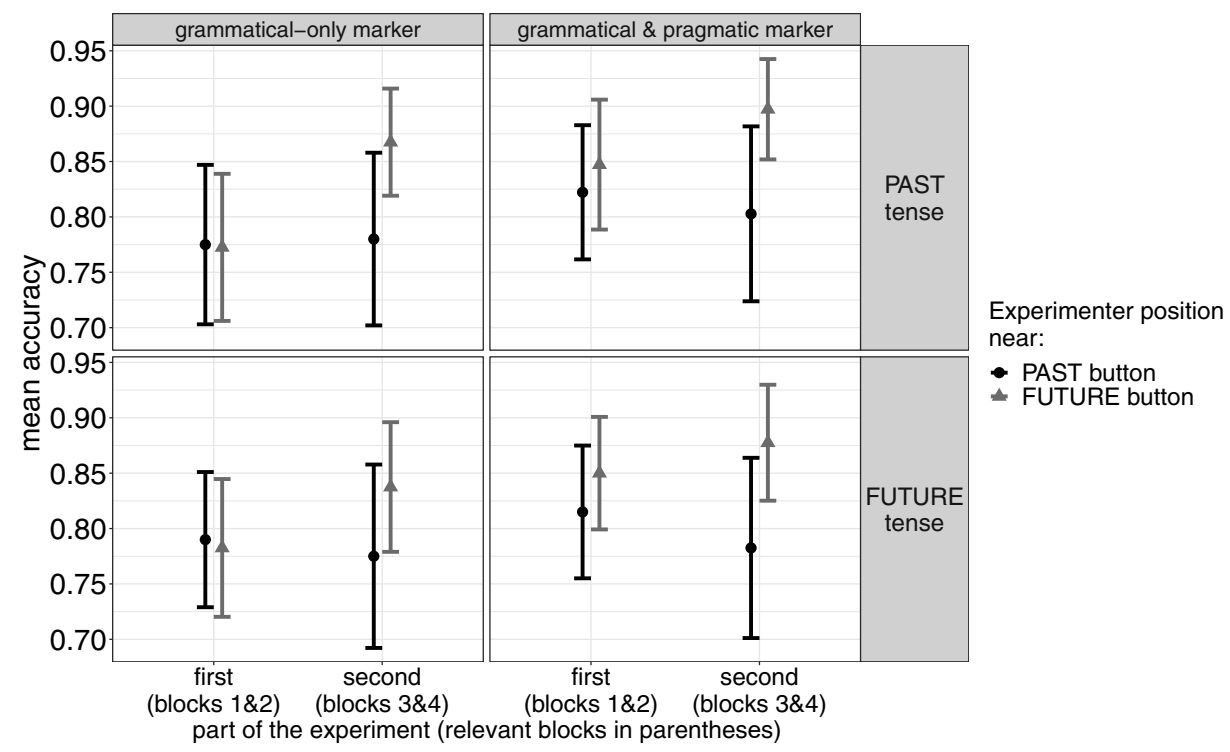

FIGURE 9. Mean accuracy rate (with 95\% confidence intervals) in experiment 2 (Pomak), with the experiment half on the x-axis (blocks 1 and 2 vs. blocks 3 and 4). NPs where temporal reference is marked only grammatically are in the left panels; NPs where temporal reference is marked grammatically and pragmatically are in the right panels. NPs in the past tense are in the top panels; NPs in the future tense are in the bottom panels. Black circles stand for trials in which the experimenter was located next to the past-corresponding button; gray triangles stand for trials in which the experimenter was located next to the future-corresponding button.

REACTION TIMES (with the variable Experiment half). In the reaction-time data, the only effect for which there was evidence is the main effect of Experiment half (estimated posterior mean $=-0.06 ; 95 \% \mathrm{CrI}=[-0.08,-0.04]$; probability that the sampled posterior was less than zero was close to 1). This effect reflects the fact, commonly found in studies that measure reaction times, that participants pressed the button faster in the second half of the experiment than in the first half, independently of the experimental condition.

The crucial outcome of this second part of the analysis is that there is no evidence for an interaction between Experiment half and any of the other experimental manipulations.

An additional visual inspection of accuracy and reaction times allows us to check more specifically the effect of the order of blocks in the experiment; see graphs in Figures 13 and 14. Recall that the past button was located to the left of the participants in blocks 1 and 3, and to their right in blocks 2 and 4. Since this was the case for all participants, we wanted to investigate whether there may be any learning effects during the 


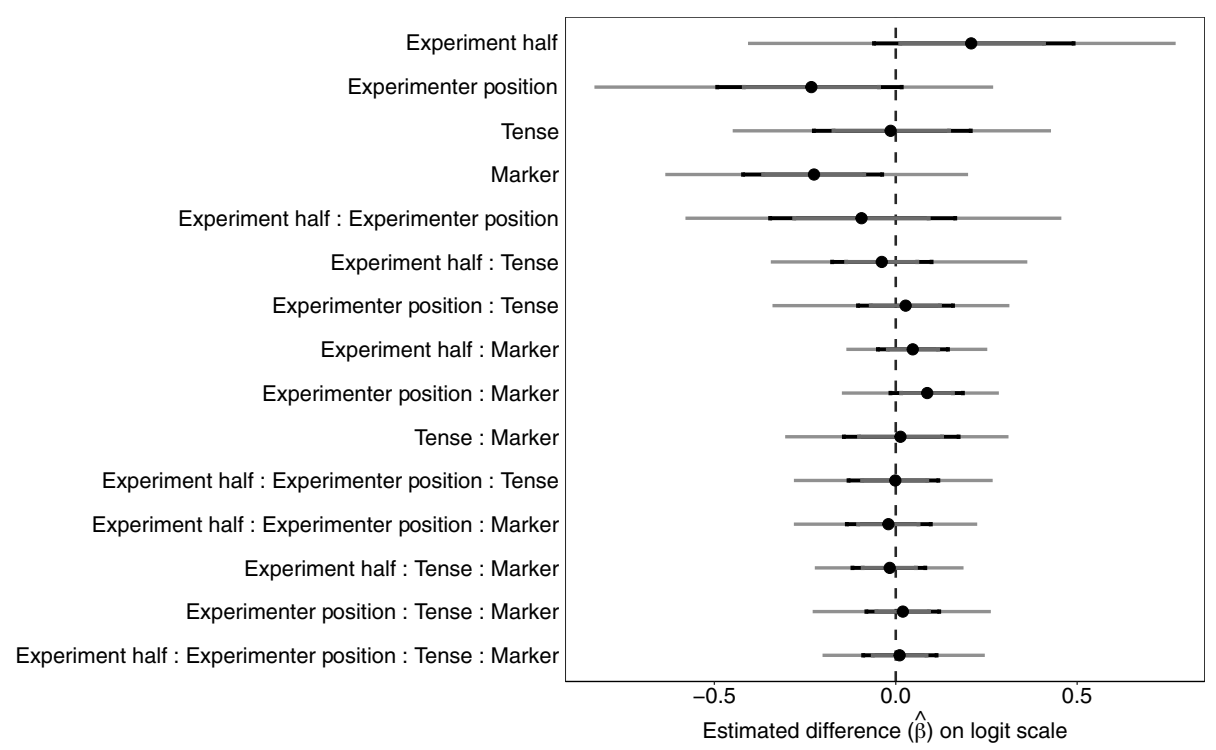

FIGURE 10. Accuracy data in experiment 2 (Pomak) - checking the effect of experiment half: posterior distributions for the fixed effects. The black dot marks the posterior mean; the outer bars mark the $95 \%$ credible intervals; the inner bars mark the $85 \%$ credible intervals; zero is marked with a vertical dashed line.

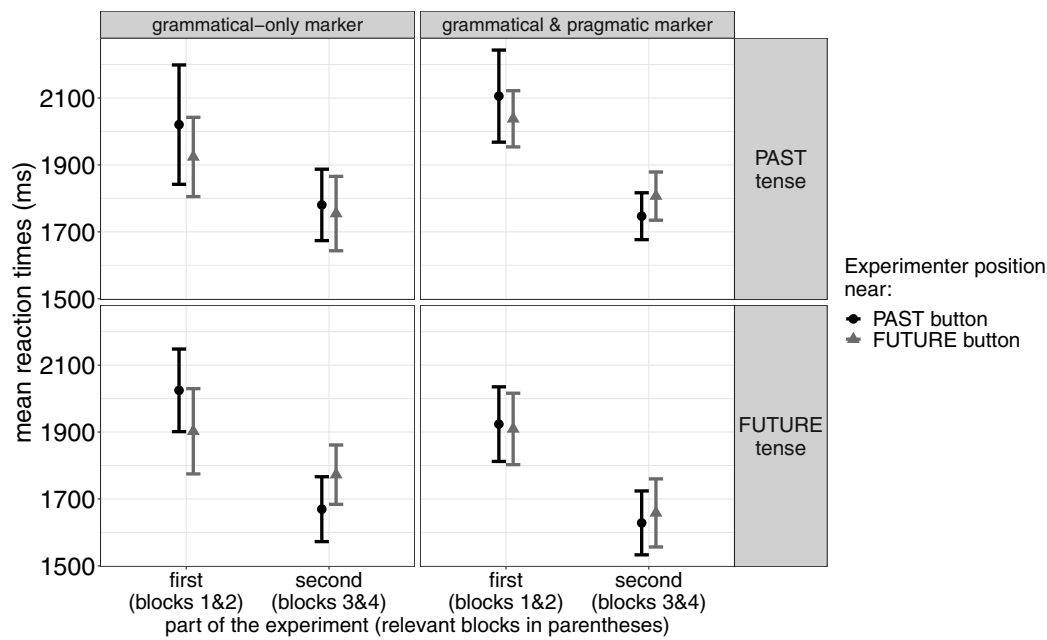

FIGURE 11. Mean reaction times in milliseconds (with 95\% confidence intervals) in experiment 2 (Pomak), with the experiment half on the x-axis (blocks 1 and 2 vs. blocks 3 and 4). NPs where temporal reference is marked only grammatically are in the left panels; NPs where tense is marked grammatically and pragmatically are in the right panels. NPs in the past tense are in the top panels; NPs in the future tense are in the bottom panels. Black circles stand for trials in which the experimenter was located next to the pastcorresponding button; gray triangles stand for trials in which the experimenter was located next to the future-corresponding button.

experiment due to some expectations that participants might have developed when moving from one block to the next.

As can be seen in Fig. 13, overall throughout the experiment participants did gradually push the buttons faster, which is expected when measuring reaction times. We ac- 


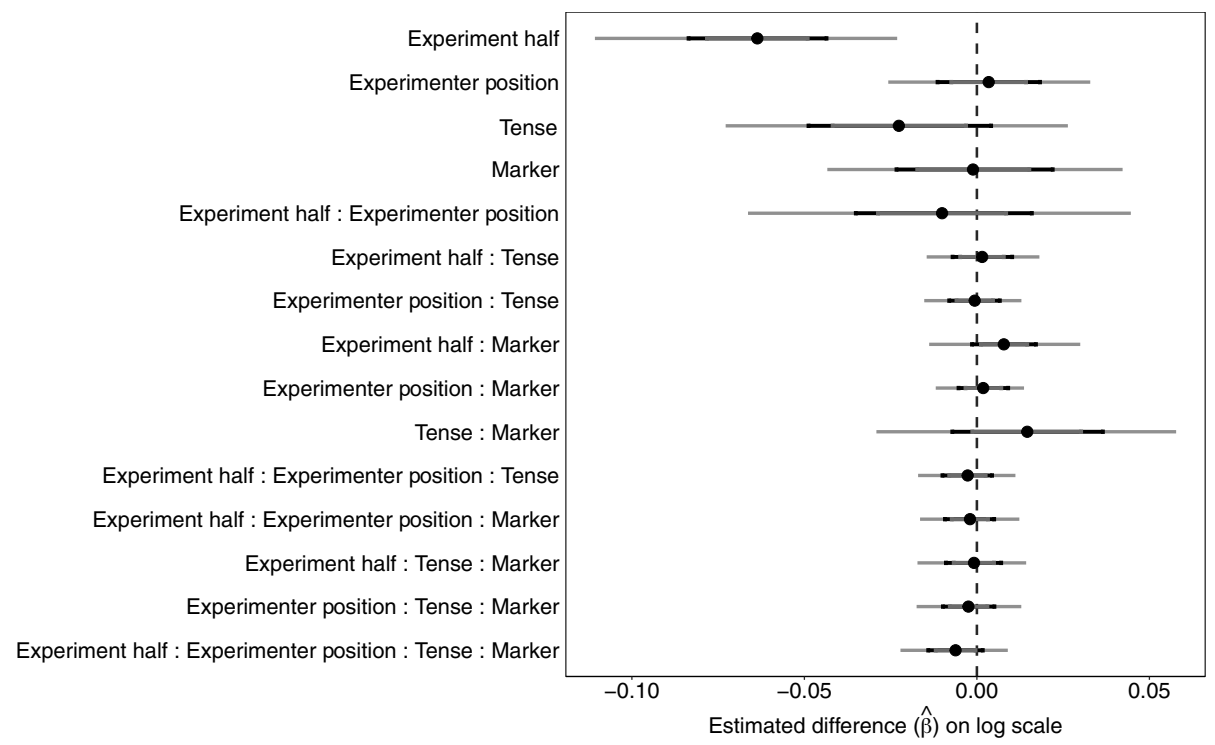

FIGURE 12. Reaction times in experiment 2 (Pomak) - checking the effect of experiment half: posterior distributions for the fixed effects. The black dot marks the posterior mean; the outer bars mark the $95 \%$ credible intervals; the inner bars mark the $85 \%$ credible intervals; zero is marked with a vertical dashed line.

knowledge that this may account for the overall faster right-handed responses that correspond to blocks 2 and 4. For this reason we refrain from drawing any conclusions about the interaction between button position and reaction times.

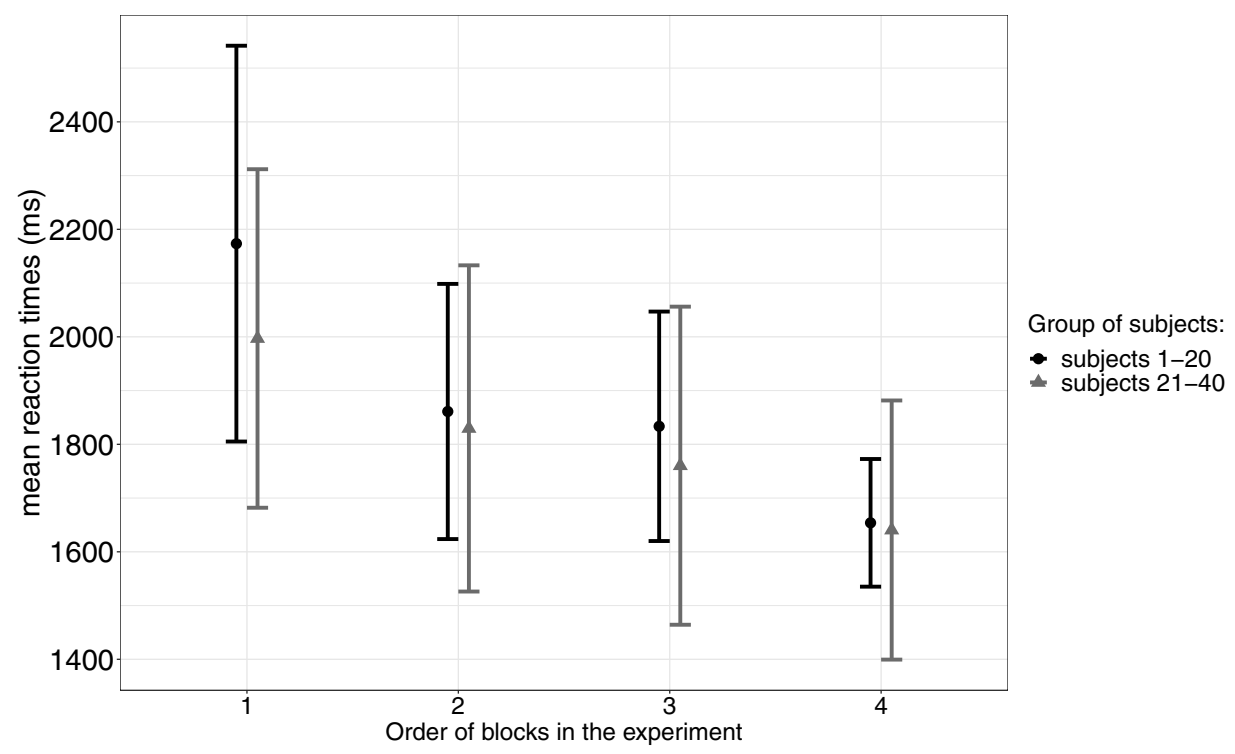

FIGURE 13. Mean reaction times in milliseconds (with 95\% confidence intervals) in experiment 2 (Pomak) in each block of the experiment (x-axis) for each group of participants. Subjects 1-20 had the experimenter on the left side for the first two blocks and then on the right side for last two blocks. Subjects $21-40$ had the experimenter to the right in the first two blocks and to the left in the last two blocks. All participants had the past button on the left in blocks 1 and 3 and on the right in blocks 2 and 4 (cf. Fig. 4). 
However, when looking at accuracy rates in the various blocks, in Fig. 14, it appears that the two groups did not get consistently more accurate throughout the blocks (compare responses for the first group in black and for the second group in gray). In particular, block 1 for the first group and block 3 for the second group, which were the same in terms of past button position and experimenter position, had the lowest accuracy rates in each group, as compared to all of the other blocks. This means that when the past button and the experimenter are both on the left side, accuracy rate decreases regardless of whether this condition appears first or third in the order of blocks.

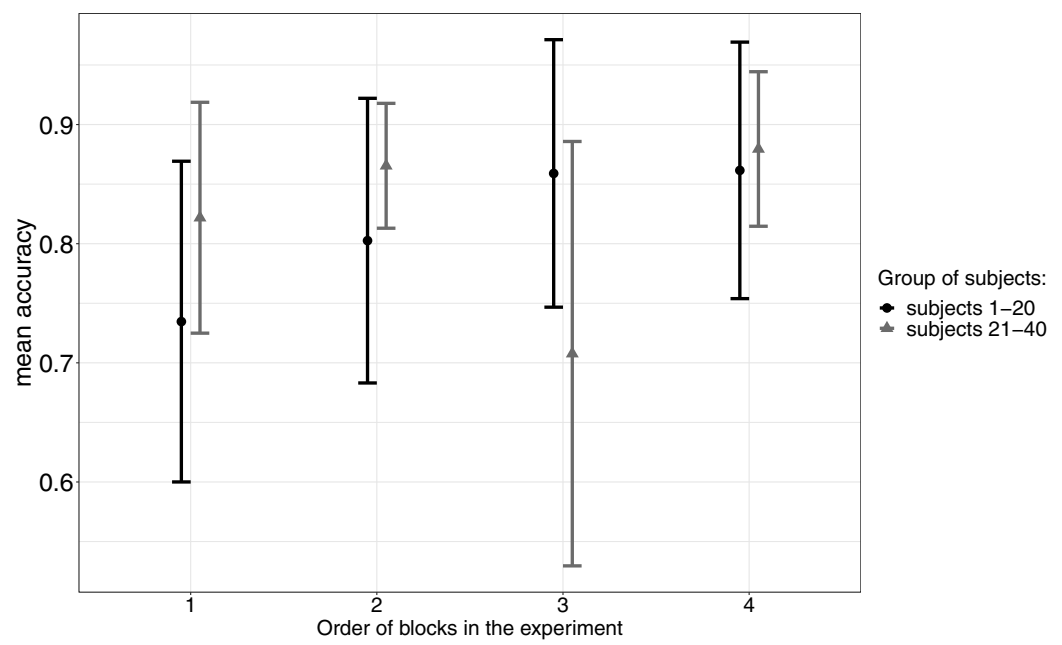

FIGURE 14. Mean accuracy rate (with 95\% confidence intervals) in experiment 2 (Pomak) in each block of the experiment (x-axis) for each group of participants. Subjects 1-20 had the experimenter on the left side for the first two blocks and then on the right side for last two blocks. Subjects 21-40 had the experimenter to the right in the first two blocks and to the left in the last two blocks. All participants had the past button on the left in blocks 1 and 3 and on the right in blocks 2 and 4 (cf. Fig. 4).

In the final part of our analysis, we consider the fact that, in our stimuli, the first-person possessive pronoun occurs more in past than in future items. This means that, in past items, there might be a stronger association with the experimenter's life, through the possessive pronoun 'my' pronounced by the experimenter herself, than in future items. To exclude the possibility that this might have had an influence on the subjects' performance, we divided the items based on whether they contained a possessive pronoun or not, and ran two more models, one for the accuracy data and one for the reaction-time data, in which the factor Tense was replaced by the factor POSSESSIVE. There was no evidence for such an effect of the possessive pronoun (either as a main effect or in interaction with the other factors). Whether or not the possessive pronoun occurred did not affect the accuracy rate or the time taken to respond. The full results of this analysis can be found in the online repository, along with the data and analysis scripts.

3.3. Discussion. The Pomak experimental data support the claim that nominal tense can provide temporal information independently of verbal tense (e.g. Nordlinger \& Sadler 2004, Adamou 2011, Lecarme 2012). The results, however, indicate that lexical and pragmatic association to past and future made the temporal interpretation more accurate. Indeed, when the auditory stimuli could be interpreted as referents to the past of the experimenter's life based both on the grammatical marker and on semantic and 
pragmatic meaning (e.g. 'the baby teeth'), participants were more accurate than on items that were not specifically related to past referents, for example, 'the dress', 'the bag', 'the coat', and where tense was marked only grammatically.

The present study also investigated whether the experimenter's position during the experiment influenced manual response times among speakers of a language where the interlocutor's sphere is associated with past referents. While we predicted that the experimenter's position near the past button would facilitate responses, we did not observe this pattern. On the one hand, the statistical analysis did not reveal an effect of the experimenter's position on speed: participants responded faster when the past button was on the right than when it was on the left, independently of linguistic cues such as tense and nonlinguistic ones like the experimenter's position. On the other hand, when past responses required the use of the left hand, the location of the experimenter did have an effect on their level of accuracy, albeit an unexpected one. More specifically, when participants used their left hand to respond to the past and the experimenter was on the participant's right side, close to the participant's right hand, participants were as accurate as when responding for the past using their right hand. This result goes against our prediction that past responses using the left hand would have been facilitated by having the experimenter on participant's left side, close to the designated past button.

What could account for the observed interaction pattern where the past/left-hand condition responses are more accurate only when the experimenter is not close to the designated button for past responses? As it stands, there is no plausible explanation for this fact. One interpretation could be that for Pomaks the right side is associated with the past and that the experimenter's position effect takes place in the noncongruent past/left-hand condition only when the experimenter is in the congruent past/rightsphere position. At present, however, our data do not allow for such an unambiguous interpretation of the button-position effect because of the order of the blocks. Another potential factor that could account for the differing patterns in the two groups is differing education levels. For instance, more-educated participants might have learned the task faster than lesser-educated participants. But participants of various education levels were equally distributed in the two groups, and therefore education cannot account for the differences in the behavior of the groups. Finally, we would like to note that the interaction between past button position and experimenter position does not appear to be due to the more or less frequent occurrence of the first-person possessive pronoun in past versus future items. The analysis of the data in which items were divided based on the occurrence of the possessive pronoun did not show evidence for such an effect.

The next experiment assessed whether the effect of the experimenter's position is language-independent. In this experiment, the same task was performed again with Pomak speakers, but this time in Greek.

4. EXPERIMENT 3. The goal of this experiment was to see whether the effect of the experimenter's position found in experiment 2 in Pomak also emerges when the task is performed in Greek, a language that does not encode tense on the NP. If the effect emerges, this would suggest that it is language-independent and could be related to the experimental design or attentional factors. However, if the experimenter-position effect is not replicated in Greek, this would suggest that it has a linguistic component.

\subsection{Methodology.}

PARTICIPANTS. The same forty L1-Pomak speakers who participated in experiment 1 were tested on experiment 3 as well. Half of them had also participated in experiment 2, but with a year between the tasks. For the Greek experiment, we were careful to involve 
as many Pomak speakers as possible who were also fluent in Greek. All participants reported fluently speaking Pomak $(M=4.83)$ and Greek $(M=4.87)$. Additionally, thirtyfour reported speaking Turkish $(M=3.95)$, and several declared having studied English. Six participants had attended at most primary school, fifteen secondary school, and nineteen university. They had all learned to read the Koran and/or attended Koranic school.

DESIGN, STIMULI, AND PROCEDURE. The design was fundamentally the same as in experiment 2. In contrast to Pomak, however, Greek does not encode tense grammatically in the NP; in fact, we refer to this property of Greek as TEMPORAL REFERENCE rather than TENSE. For this reason, we did not have a manipulation related to whether the temporal reference was encoded grammatically, as in Pomak. The auditory stimuli were recorded by the same female speaker who recorded the stimuli in the Pomak experiment. Like in the previous experiment, twenty stimuli corresponded to referents in the experimenter's past and twenty stimuli corresponded to referents that were likely to occur in the experimenter's future. To make the comparison to Pomak as similar as possible, all of the Pomak items where temporal reference was marked both grammatically and pragmatically (except for two items) were translated into Greek, where they are only pragmatically marked, as mentioned above. Instead of the grammatical-only Pomak items, new items were added for Greek containing semantic and pragmatic information for past and future reference. Another difference with respect to Pomak is that in Greek the majority of the items contained both a definite article and a first-person possessive pronoun (all twenty past items; sixteen out of twenty future items). The procedure was the same as in experiment 2, but the instructions were provided in Greek.

ANALYSIS. The treatment of the accuracy and reaction-time data for the analysis was the same as in experiment 2. The model included the factors Past button position, Experimenter position, and TEMPORAL REFERENCE (the latter factor has two levels: past and future; we avoid using the factor label 'Tense' since, as stated, tense is not encoded grammatically in Greek NPs). Unlike in the previous experiment, there was no manipulation of the way temporal reference was marked; in all items, it was marked only semantically/pragmatically (e.g. 'my baby teeth' for past vs. 'my wedding' for future). The fixed-effects part included parameters for an intercept, all of the main effects of the three factors, and all of their possible interactions. In the random effects adjusted for participants, we estimated parameters for intercepts, slopes for the three main effects and for all possible interactions, and the correlations between intercepts and slopes. In the random effects adjusted for items, we estimated parameters for intercepts; slopes for the main effect of Past button position, Experimenter position, and their interaction; and the correlations between intercepts and slopes. In a second step of the analysis, we fit models similar to the first ones, but where the Past button position factor was replaced with Experiment half.

Like in experiment 2, all variables were coded by means of 1 and -1 to center them around zero, and weakly informative priors were used. Each model ran with four Markov chains, including 3,000 iterations per chain (increased to 6,000 if required to obtain better estimation), of which the first half were discarded. We visually verified chain convergence, and checked that the $\hat{R}$ statistics for all model parameters were equal to 1 and that the number of effective samples per iteration was reasonably high.

4.2. Results. Like in experiment 2, we checked the Greek data for items with response patterns that differed substantially with respect to the rest of the items. No such items were identified in the accuracy data. From the analysis of the reaction-time data we again excluded response times that were two standard deviations faster or slower as 
compared to the overall group's performance across conditions. This resulted in the exclusion of about $4 \%$ of the reaction-time data. The appendix contains tables listing all of the Greek items along with their mean proportion of accuracy and mean reaction times.

ACCURACY. The accuracy rate in this experiment, across all conditions, was $85 \%$ on average, confirming that participants understood and performed the task without difficulty. Participants' performance in pressing the correct button with respect to the various conditions is shown in Figure 15. The analysis revealed evidence for the main effect of Temporal reference (estimated posterior mean $=-0.35 ; 95 \% \mathrm{CrI}=[-0.69,-0.04]$; probability that the posterior is less than zero $=0.98$ ) and for the interaction of Temporal reference by Past button position (estimated posterior mean $=-0.25$; 95\% CrI $=$ $[-0.46,-0.05]$; probability that the posterior is less than zero $=0.99)$. These effects indicate that when the past button was on the right side, future and past items were answered with comparable accuracy. But when the past button was on the left side, participants were less accurate on past items than on future ones. There was no evidence for the other fixed effects, whose posterior's $95 \%$ credible intervals included zero (Figure 16).

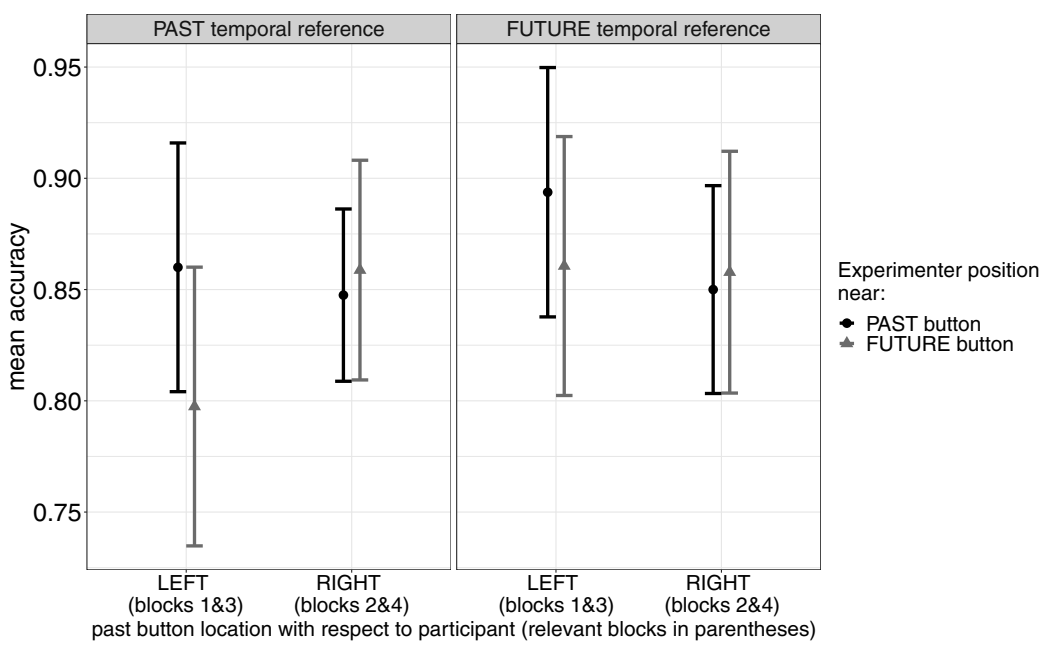

FIGURE 15. Mean accuracy rate (with 95\% confidence intervals) in experiment 3 (Greek) in relation to the various experimental manipulations: the location with respect to participants of the past-corresponding button (x-axis); sentences with past (left panel) or future temporal reference (right panel). Black circles stand for trials in which the experimenter was located next to the past-corresponding button; gray triangles stand for trials in which the experimenter was located next to the future-corresponding button.

REACTION TIMES. As in the previous experiment, only correct trials were included in the analysis of the reaction times, which are plotted in Figure 17. The only effect for which there was evidence is the main effect of Past button position (estimated posterior mean $=0.03 ; 95 \% \mathrm{CrI}=[0.02,0.04]$; probability that the posterior is less than zero was close to 0). This effect reflects the fact that participants pressed the past button faster when it was located to their right than when it was located to their left. There was no evidence for the other fixed effects in the model (Figure 18).

In the second step of the analysis, like in experiment 2, we checked the effect of the variable Experiment half. The accuracy data are shown in Figure 19 and the posteriors in Figure 20; the reaction-time data are shown in Figure 21 and the posteriors in Figure 22. 


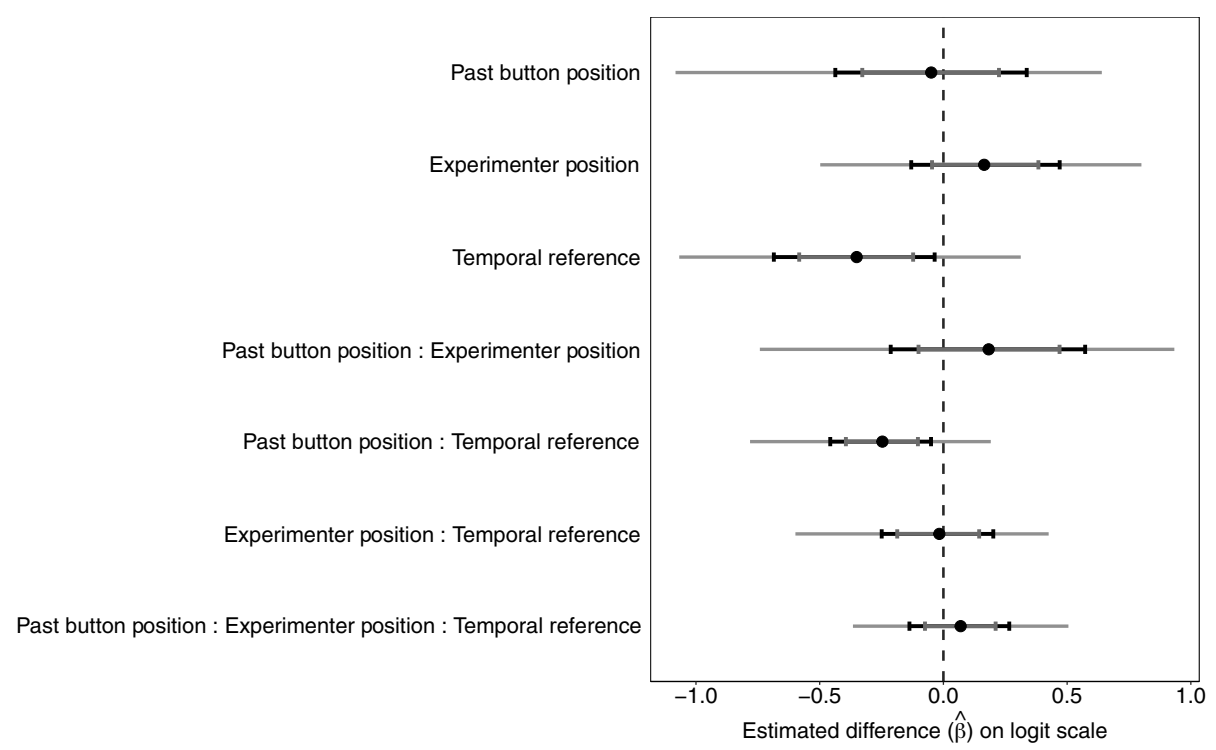

FIGURE 16. Accuracy data in experiment 3 (Greek): posterior distributions for the fixed effects. The black dot marks the posterior mean; the outer bars mark the $95 \%$ credible intervals; the inner bars mark the $85 \%$ credible intervals; zero is marked with a vertical dashed line.

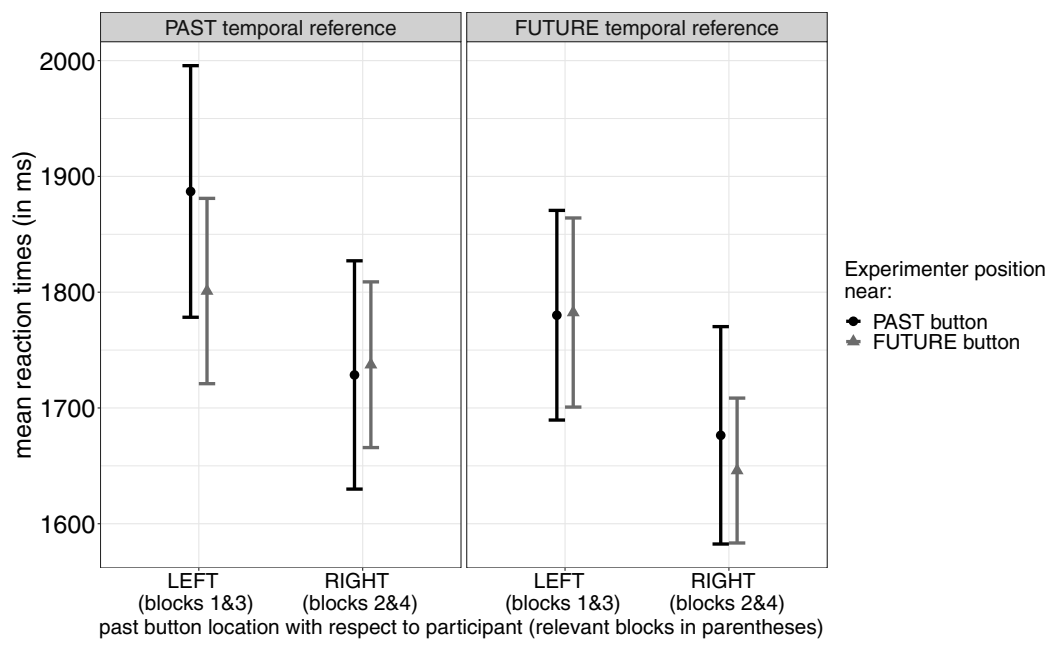

FIGURE 17. Mean reaction times in milliseconds (with 95\% confidence intervals) in experiment 3 (Greek) in relation to the various experimental manipulations: the location with respect to participants of the pastcorresponding button (x-axis); sentences with past (left panel) or future temporal reference (right panel). Black circles stand for trials in which the experimenter was located next to the past-corresponding button; gray triangles stand for trials in which the experimenter was located next to the future-corresponding button.

ACCURACY (with the variable Experiment half). In the accuracy data there was evidence only for the main effect of Temporal reference (estimated posterior mean $=$ $-0.34 ; 95 \% \mathrm{CrI}=[-0.67,-0.03]$; probability that the posterior is less than zero $=0.98$ ), reflecting a pattern parallel to the one found when the blocks were divided based on the past button position in which accuracy was higher for future than for past items. 


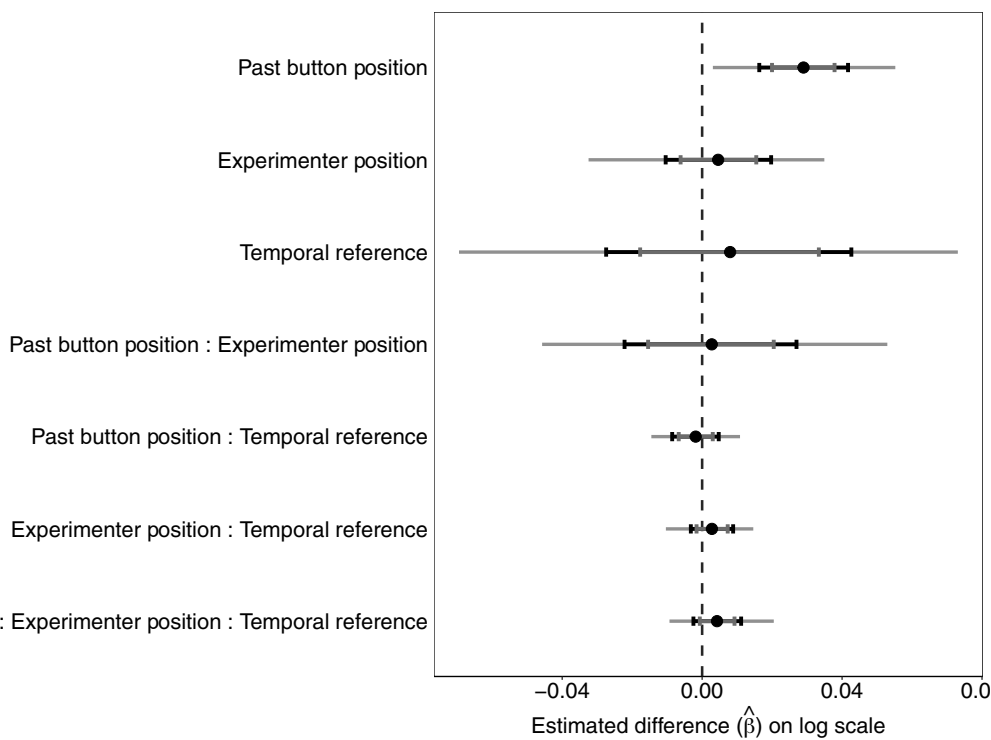

FIGURE 18. Reaction times in experiment 3 (Greek): posterior distributions for the fixed effects. The black dot marks the posterior mean; the outer bars mark the $95 \%$ credible intervals; the inner bars mark the $85 \%$ credible intervals; zero is marked with a vertical dashed line.

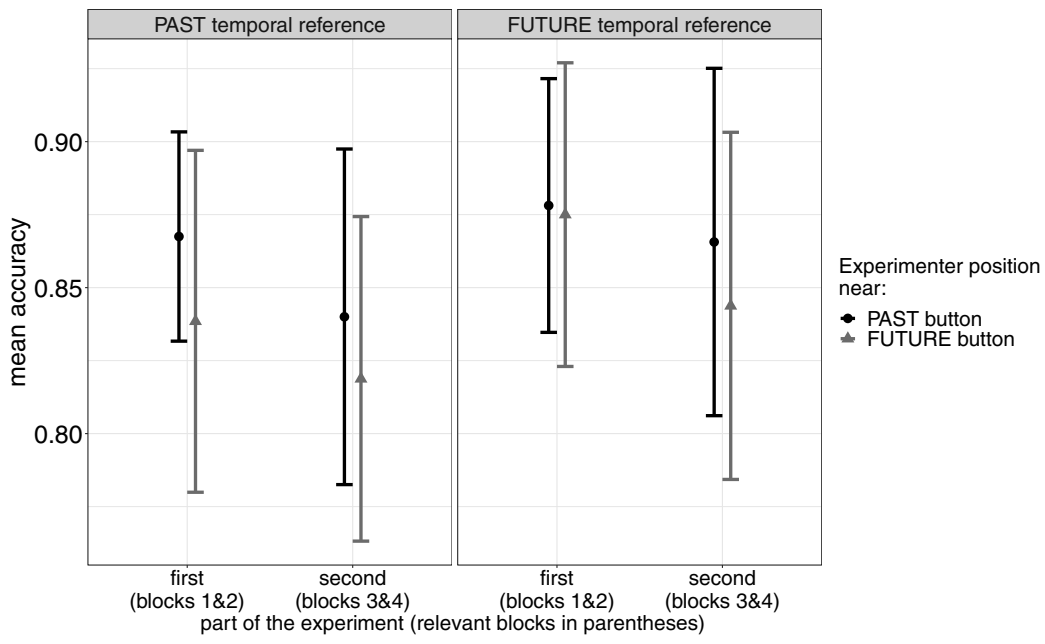

FIGURE 19. Mean accuracy rate (with 95\% confidence intervals) in experiment 3 (Greek), with the experiment half on the x-axis (blocks 1 and 2 vs. blocks 3 and 4). Sentences with past temporal reference are in the left panel; sentences with future temporal reference are in the right panel. Black circles stand for trials in which the experimenter was located next to the past-corresponding button; gray triangles stand for trials in which the experimenter was located next to the future-corresponding button.

REACTION TIMES (with the variable Experiment half). In the reaction-time data there was only evidence for the main effect of Experiment half (estimated posterior mean $=$ $-0.05 ; 95 \% \mathrm{CrI}=[-0.07,-0.04]$; probability that the posterior is less than zero was close to 1), indicating that participants overall, independently of other experimental manipulations, pressed the button faster in the second two blocks of the experiment than in the first. 


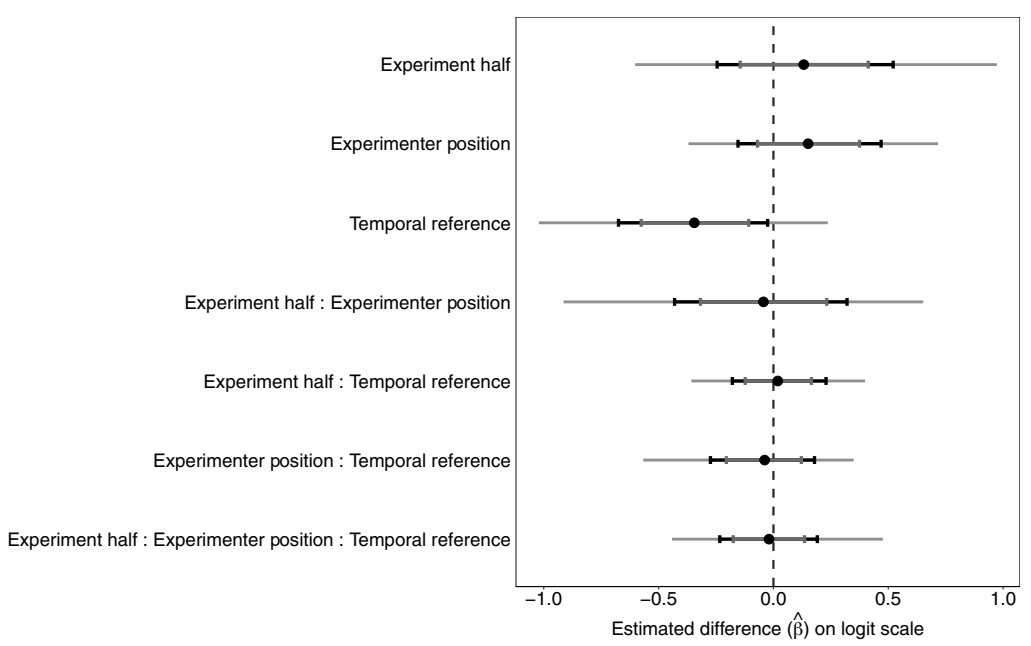

FIGURE 20. Accuracy data in experiment 3 (Greek) — checking the effect of experiment half: posterior distributions for the fixed effects. The black dot marks the posterior mean; the outer bars mark the $95 \%$ credible intervals; the inner bars mark the $85 \%$ credible intervals; zero is marked with a vertical dashed line.

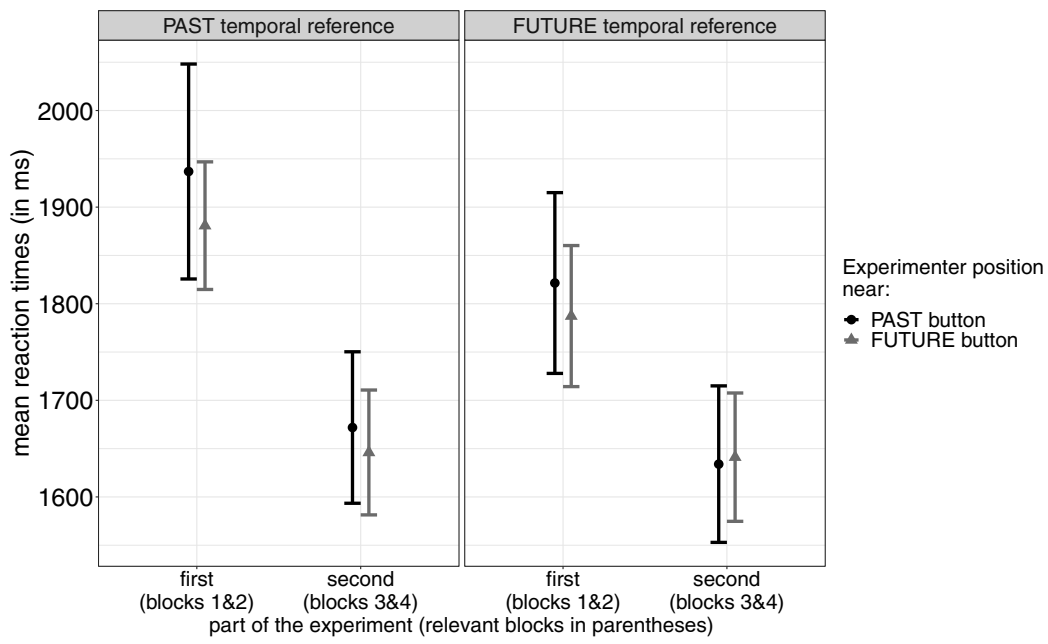

FIGURE 21. Mean reaction times in milliseconds (with 95\% confidence intervals) in experiment 3 (Greek), with the experiment half on the x-axis (blocks 1 and 2 vs. blocks 3 and 4). Sentences with past temporal reference are in the left panel; sentences with future temporal reference are in the right panel. Black circles stand for trials in which the experimenter was located next to the past-corresponding button; gray triangles stand for trials in which the experimenter was located next to the future-corresponding button.

ANALYSIS OF THE RESULTS OF EXPERIMENTS 2 AND 3 TOGETHER. In a final step of the analysis we wanted to confirm the difference between the Pomak and the Greek results, in terms of the experimenter's position in relation to the past button position. In this analysis we combined the data from the two languages (experiments 2 and 3 ). We ran one model for the accuracy data and one for the reaction times using the same procedure as before, whereby each model contained the factors Past button position (left/right), Experimenter position (near the past/future button), and LANGUAGE (Pomak/Greek). We collapsed the past and future items in each language together, since we found no evidence 


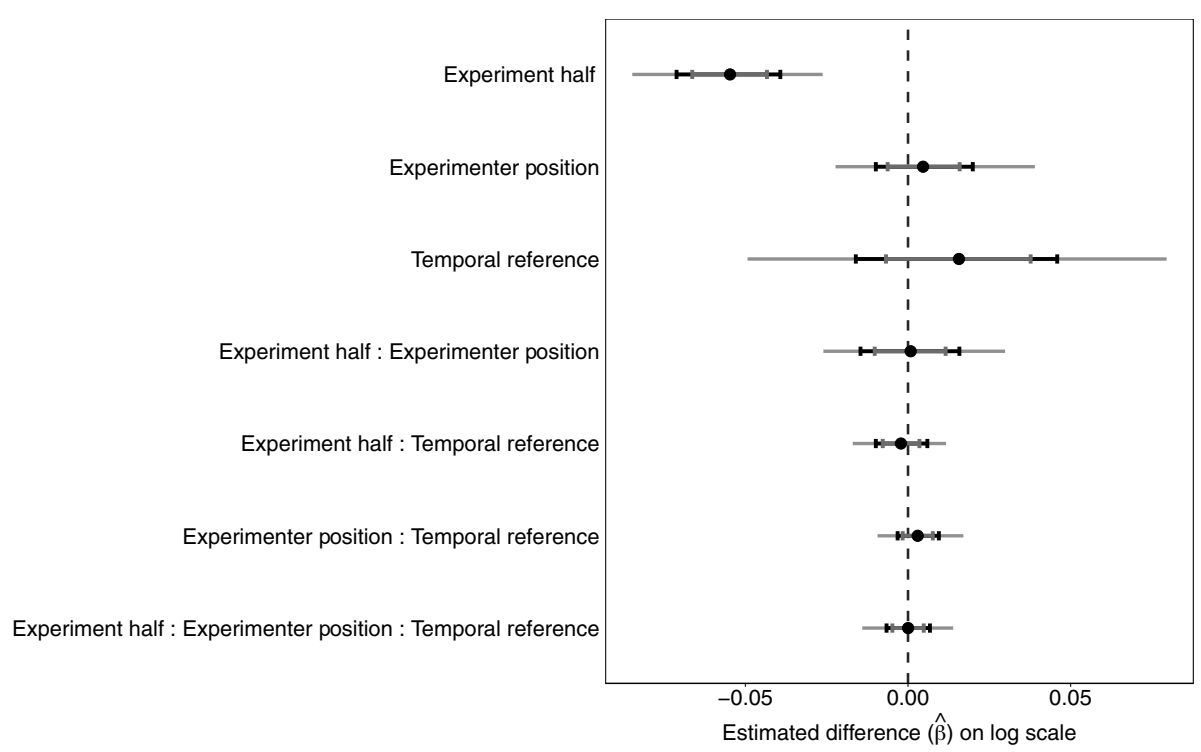

FIGURE 22. Reaction times in experiment 3 (Greek) — checking the effect of experiment half: posterior distributions for the fixed effects. The black dot marks the posterior mean; the outer bars mark the $95 \%$ credible intervals; the inner bars mark the $85 \%$ credible intervals; zero is marked with a vertical dashed line.

for an effect of Tense in either language. In the Pomak data, we also collapsed together the items that were marked only grammatically and those marked both grammatically and pragmatically. This manipulation, which was impossible to test for in Greek (where the items were pragmatically marked only), remains relevant only for the Pomak data. The significance of these results is discussed in the section on experiment 2. Moreover, we did not test the effect of Experiment half here, since there was no evidence for its significance in the analyses conducted separately for each language.

The fixed-effects part of the model included an intercept, the three main effects of the above-mentioned factors, and all possible interactions. In the random-effects part for subjects we estimated an intercept and slopes of the main effects and interaction of Past button position and Experimenter position, as well as their correlation. The same parameters were estimated in the random-effects part for all items.

Figure 23 shows the accuracy data in both languages. The model (posteriors plotted in Figure 24) confirmed that the experimenter's position interacted differently with the past button position in each language, as indicated by the three-way interaction (estimated posterior mean $=-0.26 ; 95 \% \mathrm{CrI}=[-0.47,-0.05]$; probability that the posterior is less than zero $=0.99$ ). As for the reaction times (data shown in Figure 25 and the posteriors in Figure 26), there was evidence only for the main effect of Past button position (estimated posterior mean $=0.03 ; 95 \% \mathrm{CrI}=[0.02,0.05]$; the estimated probability that the posterior is less than zero was close to 0 ), indicating that participants pressed the past button faster when it was located to their right. This effect was independent of the experimenter's position and was the same in both languages.

4.3. Discussion. In Greek, we did not find an effect of the experimenter's location on accuracy or reaction times. This suggests that the experimenter's position effect noted in Pomak is not due to general attentional processes or to the experimental design and block order; otherwise we would have found the same effect in both languages. One in- 


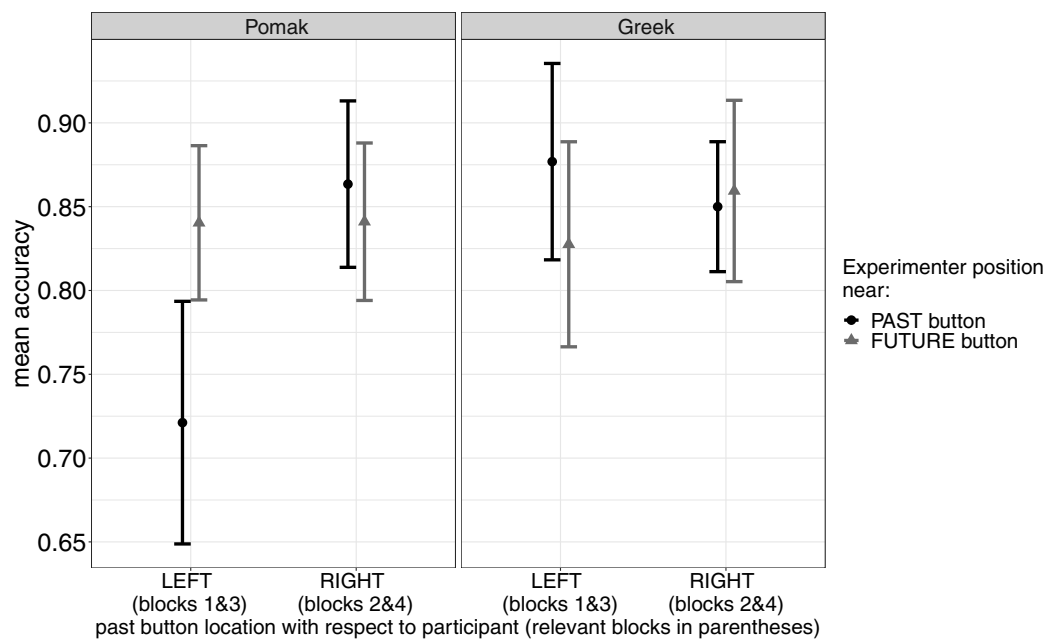

FIGURE 23. Mean accuracy rate (with 95\% confidence intervals) when comparing the Pomak (left panel) and Greek data (right panel) as regards the location with respect to participants of the past-corresponding button (x-axis). Black circles stand for trials in which the experimenter was located next to the past-corresponding button; gray triangles stand for trials in which the experimenter was located next to the future-corresponding button.

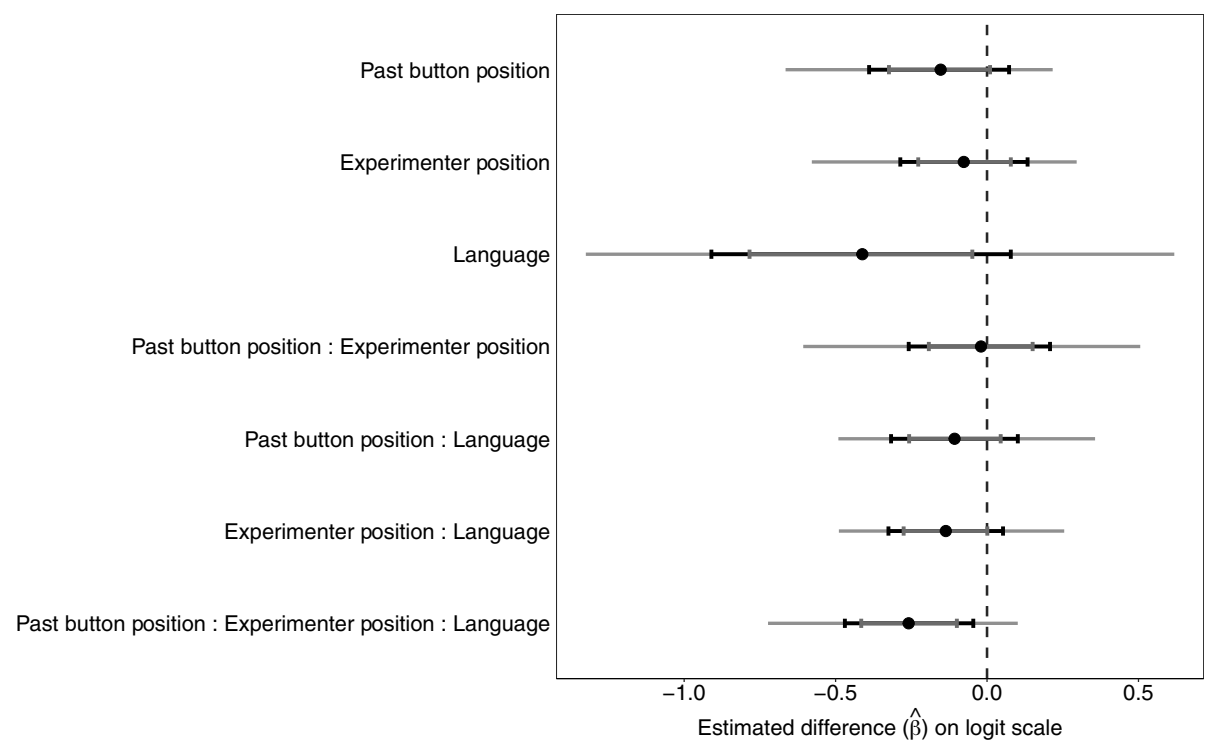

FIGURE 24. Accuracy data in the model comparing Pomak and Greek: posterior distributions for the fixed effects. The black dot marks the mean of the distribution; the outer bars mark the $95 \%$ credible intervals; the inner bars mark the $85 \%$ credible intervals; zero is marked with a vertical dashed line.

terpretation could be that the effect in Pomak is language-related, possibly stemming from the association of the two values of the $t$-article, the realis past value and the pragmatic-spatial value 'close to the interlocutor'. However, as discussed in experiment 2, at present there is no plausible explanation for why the effect is noted with lefthand/past responses when the experimenter is next to the participant's right hand. 


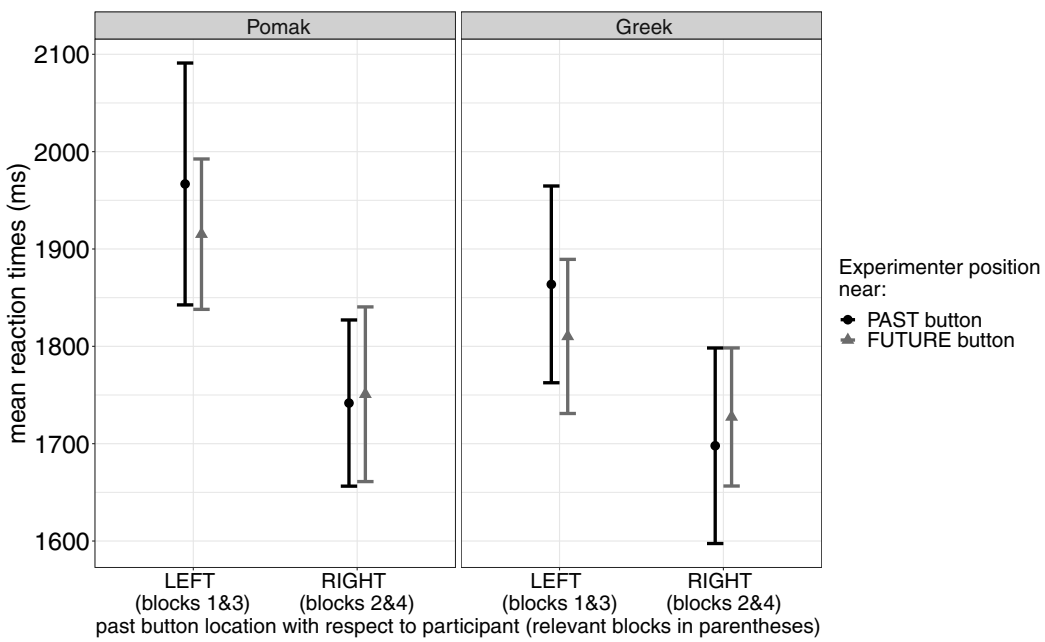

Figure 25. Mean reaction times in milliseconds (with 95\% confidence intervals) when comparing the Pomak (left panel) and Greek data (right panel) as regards the location with respect to participants of the pastcorresponding button (x-axis). Black circles stand for trials in which the experimenter was located next to the past-corresponding button; gray triangles stand for trials in which the experimenter was located next to the future-corresponding button.

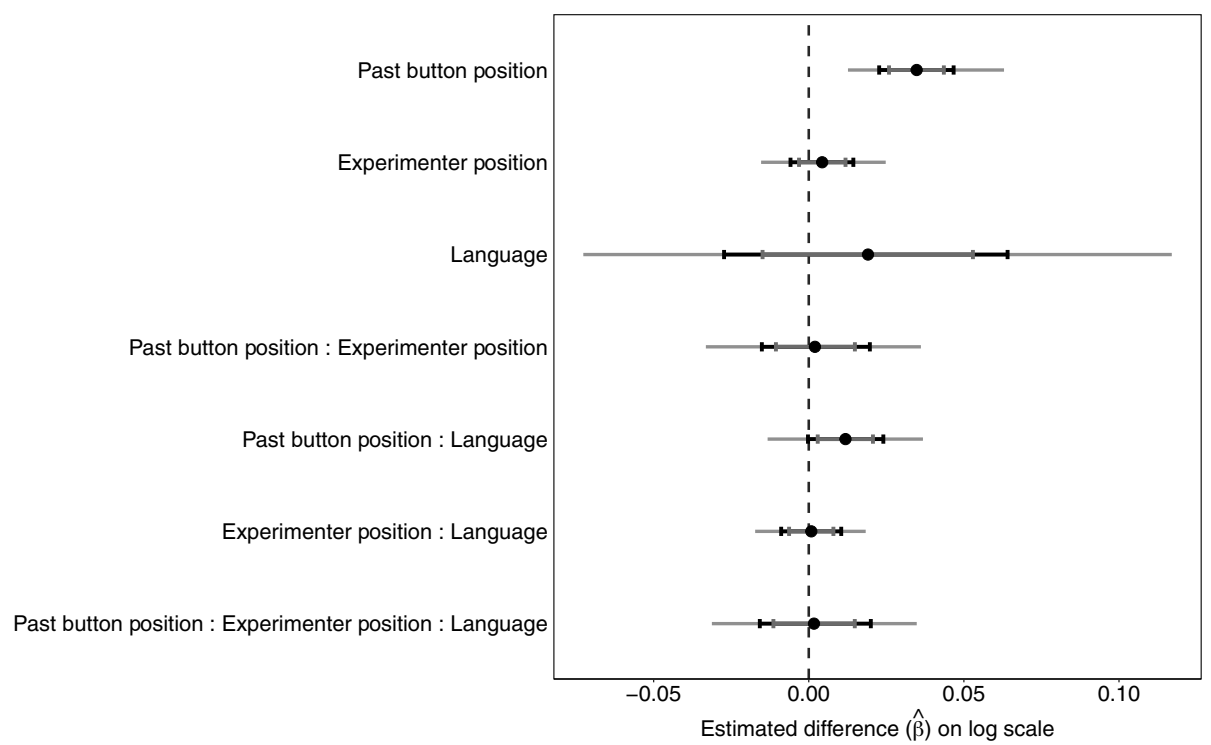

FIGURE 26. Reaction times in the model comparing Pomak and Greek: posterior distributions for the fixed effects. The black dot marks the posterior mean; the outer bars mark the $95 \%$ credible intervals; the inner bars mark the $85 \%$ credible intervals; zero is marked with a vertical dashed line.

In the analysis of the reaction times, the main effect of Past button position was the same in both languages, with participants responding faster to past reference when the button was on the right side. Recall that, as in experiment 2, blocks 2 and 4 involved right-hand responses for past. Given that participants were faster throughout the task, the faster responses using the right hand could be associated with the specificities of the experimental design. 
In addition, we found in experiment 3 in Greek that, when the past button was on the left, participants were less accurate on past items than on future items. In comparison, in the Pomak experiment accuracy of responses to past items with a past button located on the left was significantly improved when the experimenter was sitting on the participants' right side. This effect was not observed in Greek. We can hypothesize that, unlike Pomak, Greek does not offer any linguistic cues that could facilitate the processing of the past items using the left hand, thus resulting in more errors. However, this hypothesis still does not provide an adequate explanation of the observed pattern in Pomak. Finally, the reason we observe reduced accuracy in the left-hand condition in past items but not in future ones in the Greek experiment remains an open question to be further investigated.

5. General Discussion. This is the first study to provide experimental evidence relevant to the existence of nominal tense. In particular, by investigating nominal tense with an acceptability judgment task and a reaction-time experiment, it complements existing studies that document nominal tense in production using elicitation and naturalistic corpus data. In addition, our focus on Pomak, a Slavic language with clear-cut verb-noun opposition and uncontroversial use of verbal tense, helps set aside the difficulties that arise with the analysis of nominal tense in tenseless languages and in languages where the opposition between nouns and verbs may cast doubt on the reality of nominal tense.

More specifically, the acceptability judgment task in Pomak (experiment 1) demonstrates that nominal tense, as expressed through deictic suffixes, provides temporal information that is sensitive to clausal tense: agreement between nominal and verbal tense is preferred over lack of agreement. However, our study also shows that lack of temporal agreement between nominal and verbal tense is not as unacceptable as, for example, lack of gender agreement. We interpret this as evidence that an independent NP temporal interpretation may be triggered. The button-press task in Pomak (experiment 2) further shows that nominal tense can provide temporal reference in the absence of verbal tense, as deictic suffixes alone allowed the comprehenders to select a past or future interpretation, even though success rates improved for nominals that had an additional semantic and pragmatic temporal reference. The present study therefore supports an analysis of nominal tense as a grammatical phenomenon and not as an implicature (e.g. Nordlinger \& Sadler 2004, Lecarme 2012).

Finally, our study draws attention to a typologically rare linguistic phenomenon, in which the past is associated with the interlocutor's sphere. In Pomak, by manipulating the position of the experimenter, around whom we built the auditory stimuli, we explored the cognitive reality of deictic suffixes, which combine spatial, temporal, and social cues. Although our data point to the existence of an effect of experimenter's location in the Pomak experiment in comparison to the Greek experiment, we currently have no adequate theoretical explanation for this finding. Indeed, we expected the experimenter's location to provide a facilitation cue to past responses when the experimenter was near the past button. We found the opposite pattern: the experimenter's location facilitated the responses only when the experimenter was sitting on the opposite side. In addition, this effect was not consistent for responses using both hands but was restricted to left-hand responses, an asymmetric effect that calls for adequate explanation. As the study of the role of the interlocutor on the conceptualization of time is exploratory, we should interpret these results with caution. In order to better understand the role of the experimenter's position, future research should more closely examine the role of button position and its interaction with the experimenter's location. This could 
be resolved with a different design that would counterbalance both button position and the experimenter's location. Moreover, future studies could test whether the interaction patterns observed can be affected by the education levels of the participants.

In conclusion, the present study demonstrates that Pomak deictic suffixes provide temporal information at the level of the NP. We hope that it also illustrates the merits of the experimental method, and we anticipate similar findings in the other languages with nominal tense that have been reported in the literature.

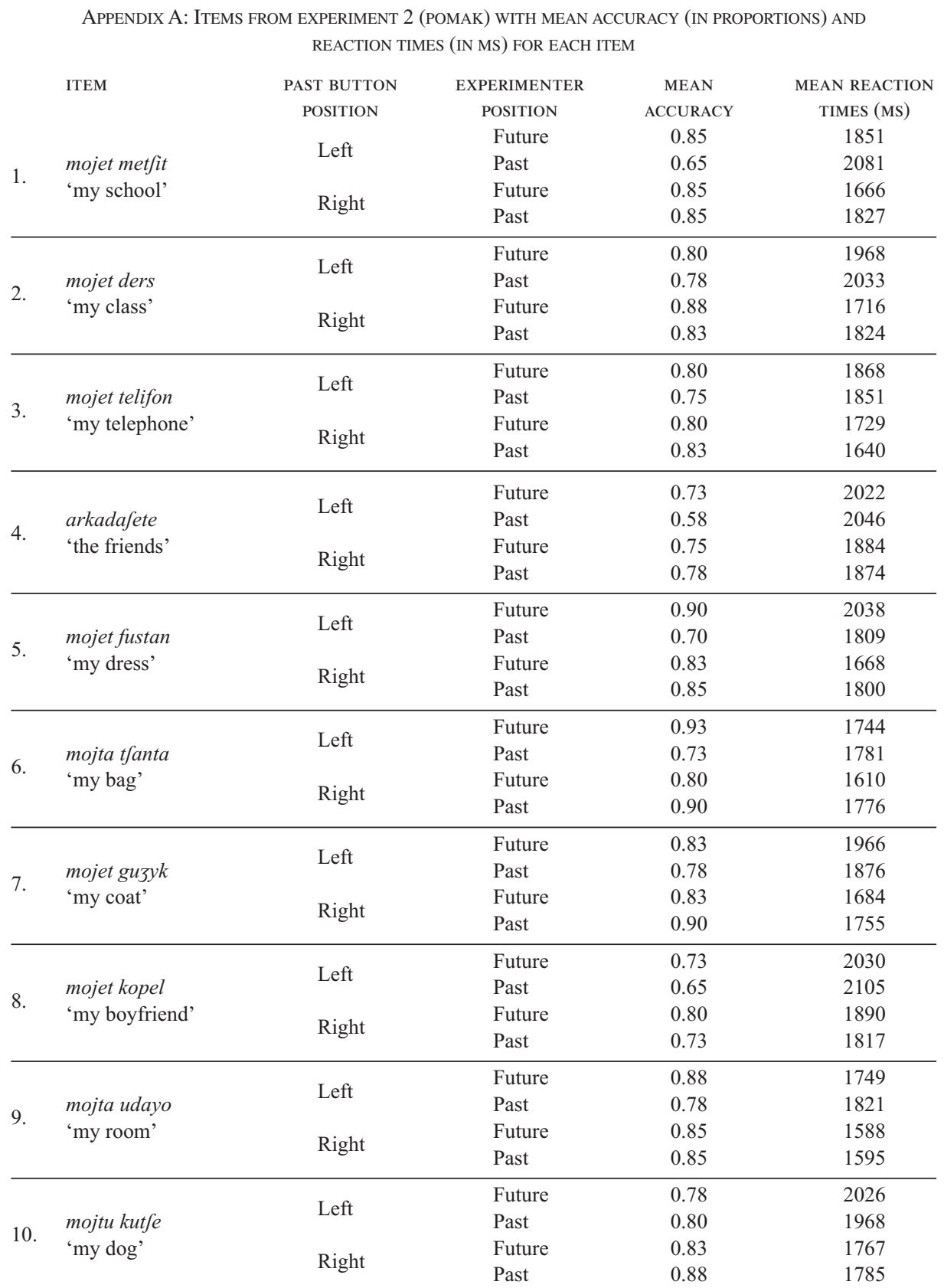

TABLE A1. Past items - grammatical marker only. 


\begin{tabular}{|c|c|c|c|c|c|}
\hline \multirow{6}{*}{11.} & \multirow[t]{2}{*}{ ITEM } & PAST BUTTON & EXPERIMENTER & MEAN & MEAN REACTION \\
\hline & & POSITION & POSITION & ACCURACY & TIMES (MS) \\
\hline & \multirow{4}{*}{$\begin{array}{l}\text { porvite zobi } \\
\text { 'the baby teeth' }\end{array}$} & \multirow{2}{*}{ Left } & Future & 0.93 & 2069 \\
\hline & & & Past & 0.78 & 1928 \\
\hline & & \multirow{2}{*}{ Right } & Future & 0.83 & 1859 \\
\hline & & & Past & 0.90 & 1770 \\
\hline \multirow{4}{*}{12.} & \multirow{4}{*}{$\begin{array}{l}\text { dolnet met/it } \\
\text { 'the Koran school' }\end{array}$} & \multirow{2}{*}{ Left } & Future & 0.90 & 2143 \\
\hline & & & Past & 0.63 & 1990 \\
\hline & & \multirow{2}{*}{ Right } & Future & 0.75 & 1715 \\
\hline & & & Past & 0.80 & 1929 \\
\hline \multirow{4}{*}{13.} & \multirow{4}{*}{$\begin{array}{l}\text { mojet verespit } \\
\text { 'my bicycle' }\end{array}$} & \multirow{2}{*}{ Left } & Future & 0.83 & 1816 \\
\hline & & & Past & 0.75 & 1590 \\
\hline & & \multirow{2}{*}{ Right } & Future & 0.85 & 1725 \\
\hline & & & Past & 0.95 & 1748 \\
\hline \multirow{4}{*}{14.} & \multirow{4}{*}{$\begin{array}{l}\text { mojet befik } \\
\text { 'my baby bed' }\end{array}$} & \multirow{2}{*}{ Left } & Future & 0.88 & 1927 \\
\hline & & & Past & 0.75 & 1921 \\
\hline & & \multirow{2}{*}{ Right } & Future & 0.15 & 1761 \\
\hline & & & Past & 0.05 & 2130 \\
\hline \multirow{4}{*}{15.} & \multirow{4}{*}{$\begin{array}{l}\text { mojta lulka } \\
\text { 'my cradle' }\end{array}$} & \multirow{2}{*}{ Left } & Future & 0.93 & 1882 \\
\hline & & & Past & 0.78 & 1967 \\
\hline & & \multirow{2}{*}{ Right } & Future & 0.85 & 1931 \\
\hline & & & Past & 0.90 & 1646 \\
\hline \multirow{4}{*}{16.} & \multirow{4}{*}{$\begin{array}{l}\text { mojta kukla } \\
\text { 'my doll' }\end{array}$} & \multirow{2}{*}{ Left } & Future & 0.90 & 2023 \\
\hline & & & Past & 0.73 & 2092 \\
\hline & & \multirow{2}{*}{ Right } & Future & 0.95 & 1905 \\
\hline & & & Past & 0.90 & 1782 \\
\hline & & Left & Future & 0.93 & 1794 \\
\hline 17 & mojtu kuritu & Left & Past & 0.75 & 1877 \\
\hline $1 /$. & 'my baby bath' & Right & Future & 0.85 & 1738 \\
\hline & & Kignt & Past & 0.85 & 1794 \\
\hline & & & Future & 0.78 & 2303 \\
\hline 18 & daskalitsata & Left & Past & 0.73 & 2251 \\
\hline 18. & 'the schoolteacher' & Right & Future & 0.85 & 1969 \\
\hline & & Kignt & Past & 0.88 & 2035 \\
\hline & & & Future & 0.88 & 1896 \\
\hline 10 & mojet jurgan & Left & Past & 0.73 & 1819 \\
\hline 19. & 'my baby sleeping bag' & Right & Future & 0.93 & 1702 \\
\hline & & Right & Past & 0.98 & 1671 \\
\hline & & I f & Future & 0.85 & 1949 \\
\hline 20 & mojta fife & Left & Past & 0.73 & 2199 \\
\hline 20. & 'my baby bottle' & Rioht & Future & 0.95 & 1852 \\
\hline & & Right & Past & 0.90 & 1746 \\
\hline
\end{tabular}

TABLE A2. Past items - grammatical and pragmatic marker.

\begin{tabular}{|c|c|c|c|c|c|}
\hline & ITEM & PAST BUTTON & EXPERIMENTER & MEAN & MEAN REACTION \\
\hline \multirow{5}{*}{1.} & \multirow{5}{*}{$\begin{array}{l}\text { metfiten } \\
\text { 'the school' }\end{array}$} & POSITION & POSITION & ACCURACY & TIMES (MS) \\
\hline & & \multirow{2}{*}{ Left } & Future & 0.80 & 1881 \\
\hline & & & Past & 0.60 & 1789 \\
\hline & & \multirow{2}{*}{ Right } & Future & 0.83 & 1602 \\
\hline & & & Past & 0.70 & 1736 \\
\hline \multirow{4}{*}{2.} & \multirow{4}{*}{$\begin{array}{l}\text { novana ko/ta } \\
\text { 'the new house' }\end{array}$} & \multirow{2}{*}{ Left } & Future & 0.88 & 2018 \\
\hline & & & Past & 0.85 & 2188 \\
\hline & & \multirow{2}{*}{ Right } & Future & 0.88 & 1816 \\
\hline & & & Past & 0.90 & 1931 \\
\hline
\end{tabular}




\begin{tabular}{|c|c|c|c|c|c|}
\hline & ITEM & $\begin{array}{c}\text { PAST BUTTON } \\
\text { POSITION }\end{array}$ & $\begin{array}{c}\text { EXPERIMENTER } \\
\text { POSITION }\end{array}$ & $\begin{array}{c}\text { MEAN } \\
\text { ACCURACY }\end{array}$ & $\begin{array}{l}\text { MEAN REACTION } \\
\text { TIMES (MS) }\end{array}$ \\
\hline 3. & $\begin{array}{l}\text { mutoran } \\
\text { 'the scooter' }\end{array}$ & $\begin{array}{l}\text { Left } \\
\text { Right }\end{array}$ & $\begin{array}{l}\text { Future } \\
\text { Past } \\
\text { Future } \\
\text { Past }\end{array}$ & $\begin{array}{l}0.83 \\
0.75 \\
0.88 \\
0.88\end{array}$ & $\begin{array}{l}1557 \\
1677 \\
1601 \\
1514\end{array}$ \\
\hline 4. & $\begin{array}{l}\text { mojnu kutfe } \\
\text { 'my dog' }\end{array}$ & $\begin{array}{l}\text { Left } \\
\text { Right }\end{array}$ & $\begin{array}{l}\text { Future } \\
\text { Past } \\
\text { Future } \\
\text { Past }\end{array}$ & $\begin{array}{l}0.80 \\
0.70 \\
0.68 \\
0.88\end{array}$ & $\begin{array}{l}2044 \\
1931 \\
1778 \\
1740\end{array}$ \\
\hline 5. & $\begin{array}{l}\text { tumafilen } \\
\text { 'the car' }\end{array}$ & $\begin{array}{l}\text { Left } \\
\text { Right }\end{array}$ & $\begin{array}{l}\text { Future } \\
\text { Past } \\
\text { Future } \\
\text { Past }\end{array}$ & $\begin{array}{l}0.85 \\
0.75 \\
0.78 \\
0.95\end{array}$ & $\begin{array}{l}1608 \\
1806 \\
1727 \\
1694\end{array}$ \\
\hline 6. & $\begin{array}{l}\text { kismeten mi } \\
\text { 'my destiny' }\end{array}$ & $\begin{array}{l}\text { Left } \\
\text { Right }\end{array}$ & $\begin{array}{l}\text { Future } \\
\text { Past } \\
\text { Future } \\
\text { Past }\end{array}$ & $\begin{array}{l}0.85 \\
0.75 \\
0.80 \\
0.83\end{array}$ & $\begin{array}{l}1784 \\
2026 \\
1615 \\
1713\end{array}$ \\
\hline 7. & $\begin{array}{l}\text { arkadafene } \\
\text { 'the friends' }\end{array}$ & Right & $\begin{array}{l}\text { Future } \\
\text { Past } \\
\text { Future } \\
\text { Past }\end{array}$ & $\begin{array}{l}0.80 \\
0.75 \\
0.85 \\
0.85\end{array}$ & $\begin{array}{l}2158 \\
2182 \\
1839 \\
2013\end{array}$ \\
\hline 8. & $\begin{array}{l}\text { mojne dersve } \\
\text { 'my classes' }\end{array}$ & $\begin{array}{l}\text { Left } \\
\text { Right }\end{array}$ & $\begin{array}{l}\text { Future } \\
\text { Past } \\
\text { Future } \\
\text { Past }\end{array}$ & $\begin{array}{l}0.73 \\
0.73 \\
0.80 \\
0.78\end{array}$ & $\begin{array}{l}2036 \\
1984 \\
1665 \\
1759\end{array}$ \\
\hline 9. & $\begin{array}{l}\text { mojne dykjan } \\
\text { 'my shop' }\end{array}$ & $\begin{array}{l}\text { Left } \\
\text { Right }\end{array}$ & $\begin{array}{l}\text { Future } \\
\text { Past } \\
\text { Future } \\
\text { Past }\end{array}$ & $\begin{array}{l}0.83 \\
0.68 \\
0.85 \\
0.85\end{array}$ & $\begin{array}{l}1759 \\
1623 \\
1645 \\
1551\end{array}$ \\
\hline 10. & $\begin{array}{l}\text { mojna kuliba } \\
\text { 'my hut' }\end{array}$ & $\begin{array}{l}\text { Left } \\
\text { Right }\end{array}$ & $\begin{array}{l}\text { Future } \\
\text { Past } \\
\text { Future } \\
\text { Past }\end{array}$ & $\begin{array}{l}0.78 \\
0.68 \\
0.75 \\
0.83\end{array}$ & $\begin{array}{l}2052 \\
2027 \\
1586 \\
1602\end{array}$ \\
\hline
\end{tabular}

TABLE A3. Future items - grammatical marker only.

\begin{tabular}{|c|c|c|c|c|c|}
\hline & ITEM & PAST BUTTON & EXPERIMENTER & MEAN & MEAN REACTION \\
\hline \multirow{5}{*}{11.} & \multirow{5}{*}{$\begin{array}{l}\text { sfadbana } \\
\text { 'the wedding' }\end{array}$} & POSITION & POSITION & ACCURACY & TIMES (MS) \\
\hline & & \multirow{2}{*}{ Left } & Future & 0.88 & 1983 \\
\hline & & & Past & 0.83 & 1916 \\
\hline & & \multirow{2}{*}{ Right } & Future & 0.90 & 1761 \\
\hline & & & Past & 0.93 & 1851 \\
\hline \multirow{4}{*}{12.} & \multirow{4}{*}{$\begin{array}{l}\text { mojen tfyljak } \\
\text { 'my husband' }\end{array}$} & \multirow{2}{*}{ Left } & Future & 0.90 & 1884 \\
\hline & & & Past & 0.75 & 1850 \\
\hline & & \multirow{2}{*}{ Right } & Future & 0.85 & 1844 \\
\hline & & & Past & 0.93 & 1776 \\
\hline \multirow{4}{*}{13.} & \multirow{4}{*}{$\begin{array}{l}\text { mojne deti } \\
\text { 'my children' }\end{array}$} & \multirow{2}{*}{ Left } & Future & 0.93 & 1791 \\
\hline & & & Past & 0.73 & 1853 \\
\hline & & \multirow{2}{*}{ Right } & Future & 0.83 & 1750 \\
\hline & & & Past & 0.90 & 1656 \\
\hline \multirow{4}{*}{14.} & \multirow{4}{*}{$\begin{array}{l}\text { mojne torune } \\
\text { 'my grandchildren' }\end{array}$} & \multirow{2}{*}{ Left } & Future & 0.85 & 1790 \\
\hline & & & Past & 0.75 & 1962 \\
\hline & & \multirow{2}{*}{ Right } & Future & 0.85 & 1746 \\
\hline & & & Past & 0.80 & 1600 \\
\hline
\end{tabular}




\begin{tabular}{|c|c|c|c|c|c|}
\hline & ITEM & PAST BUTTON & EXPERIMENTER & MEAN & MEAN REACTION \\
\hline \multirow{5}{*}{15.} & \multirow{5}{*}{$\begin{array}{l}\text { diplomanu } \\
\text { 'the driving license' }\end{array}$} & & POSITION & ACCURACY & TIMES (MS) \\
\hline & & \multirow{2}{*}{ Left } & Future & 0.90 & 1701 \\
\hline & & & Past & 0.70 & 1695 \\
\hline & & \multirow{2}{*}{ Right } & Future & 0.90 & 1504 \\
\hline & & & Past & 0.85 & 1677 \\
\hline \multirow{4}{*}{16.} & \multirow{4}{*}{$\begin{array}{l}\text { rabutana } \\
\text { 'the work' }\end{array}$} & \multirow{2}{*}{ Left } & Future & 0.80 & 1953 \\
\hline & & & Past & 0.65 & 1772 \\
\hline & & \multirow{2}{*}{ Right } & Future & 0.83 & 1605 \\
\hline & & & Past & 0.93 & 1719 \\
\hline \multirow{4}{*}{17.} & \multirow{4}{*}{$\begin{array}{l}\text { gelinlikan } \\
\text { 'the wedding dress' }\end{array}$} & \multirow{2}{*}{ Left } & Future & 0.85 & 1633 \\
\hline & & & Past & 0.63 & 1798 \\
\hline & & \multirow{2}{*}{ Right } & Future & 0.88 & 1539 \\
\hline & & & Past & 0.85 & 1579 \\
\hline \multirow{4}{*}{18.} & \multirow{4}{*}{$\begin{array}{l}\text { porstenan } \\
\text { 'the wedding ring' }\end{array}$} & \multirow{2}{*}{ Left } & Future & 0.83 & 1669 \\
\hline & & & Past & 0.70 & 1791 \\
\hline & & \multirow{2}{*}{ Right } & Future & 0.90 & 1513 \\
\hline & & & Past & 0.88 & 1541 \\
\hline \multirow{4}{*}{19.} & \multirow{4}{*}{$\begin{array}{l}\text { ajlikan } \\
\text { 'the salary' }\end{array}$} & \multirow{2}{*}{ Left } & Future & 0.80 & 1774 \\
\hline & & & Past & 0.73 & 1697 \\
\hline & & \multirow{2}{*}{ Right } & Future & 0.90 & 1522 \\
\hline & & & Past & 0.85 & 1396 \\
\hline \multirow{4}{*}{20.} & \multirow{4}{*}{$\begin{array}{l}\text { glavenikan } \\
\text { 'the fiancé' }\end{array}$} & \multirow{2}{*}{ Left } & Future & 0.83 & 1955 \\
\hline & & & Past & 0.70 & 2023 \\
\hline & & \multirow{2}{*}{ Right } & Future & 0.90 & 1925 \\
\hline & & & Past & 0.93 & 1880 \\
\hline
\end{tabular}

TABLE A4. Future items - grammatical and pragmatic marker.

APPENDIX B: ITEMS FROM EXPERIMENT 3 (GREEK) WITH MEAN ACCURACY (IN PROPORTIONS) AND REACTION TIMES (IN MS) FOR EACH ITEM

\begin{tabular}{|c|c|c|c|c|c|}
\hline \multirow{5}{*}{1.} & ITEM & $\begin{array}{c}\text { PAST BUTTON } \\
\text { POSITION }\end{array}$ & $\begin{array}{c}\text { EXPERIMENTER } \\
\text { POSITION }\end{array}$ & $\begin{array}{c}\text { MEAN } \\
\text { ACCURACY }\end{array}$ & $\begin{array}{l}\text { MEAN REACTION } \\
\text { TIMES (MS) }\end{array}$ \\
\hline & \multirow{4}{*}{$\begin{array}{l}\eta \pi \imath \pi \hat{\imath} \lambda \alpha \mu \text { ov } \\
\text { 'my pacifier' }\end{array}$} & \multirow{2}{*}{ Left } & Future & 0.85 & 1752 \\
\hline & & & Past & 0.88 & 1697 \\
\hline & & \multirow{2}{*}{ Right } & Future & 0.88 & 1650 \\
\hline & & & Past & 0.90 & 1648 \\
\hline \multirow{4}{*}{2.} & \multirow{4}{*}{ 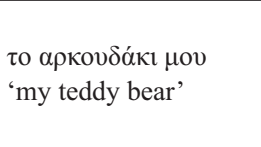 } & \multirow{2}{*}{ Left } & Future & 0.82 & 1579 \\
\hline & & & Past & 0.90 & 1823 \\
\hline & & \multirow{2}{*}{ Right } & Future & 0.88 & 1692 \\
\hline & & & Past & 0.88 & 1546 \\
\hline \multirow{4}{*}{3.} & \multirow{4}{*}{$\begin{array}{l}\tau \alpha \sigma \chi 0 \lambda \text { ıк⿰́ } \mu \text { ov } \\
\text { 'my school materials' }\end{array}$} & \multirow{2}{*}{ Left } & Future & 0.82 & 1827 \\
\hline & & & Past & 0.88 & 1830 \\
\hline & & \multirow{2}{*}{ Right } & Future & 0.88 & 1826 \\
\hline & & & Past & 0.88 & 1598 \\
\hline \multirow{4}{*}{4.} & \multirow{4}{*}{$\begin{array}{l}\tau \alpha \pi \alpha \imath \chi v i ́ \delta 1 \alpha \mu \text { ov } \\
\text { 'my toys' }\end{array}$} & \multirow{2}{*}{ Left } & Future & 0.87 & 1861 \\
\hline & & & Past & 0.88 & 1921 \\
\hline & & \multirow{2}{*}{ Right } & Future & 0.88 & 1793 \\
\hline & & & Past & 0.90 & 1791 \\
\hline \multirow{4}{*}{5.} & \multirow{4}{*}{$\begin{array}{l}\text { ol } \delta \alpha \sigma \kappa \alpha ́ \lambda \varepsilon \varsigma \mu \mathrm{ov} \\
\text { 'my teachers' }\end{array}$} & \multirow{2}{*}{ Left } & Future & 0.82 & 1920 \\
\hline & & & Past & 0.85 & 2013 \\
\hline & & \multirow{2}{*}{ Right } & Future & 0.85 & 1771 \\
\hline & & & Past & 0.83 & 1760 \\
\hline
\end{tabular}




\begin{tabular}{|c|c|c|c|c|c|}
\hline & ITEM & PAST BUTTON & EXPERIMENTER & MEAN & MEAN REACTION \\
\hline \multirow{5}{*}{6.} & \multirow{5}{*}{ 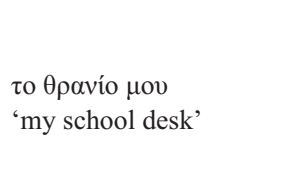 } & POSITION & POSITION & ACCURACY & TIMES (MS) \\
\hline & & \multirow{2}{*}{ Left } & Future & 0.79 & 1890 \\
\hline & & & Past & 0.90 & 1844 \\
\hline & & \multirow{2}{*}{ Right } & Future & 0.93 & 1657 \\
\hline & & & Past & 0.83 & 1619 \\
\hline \multirow{4}{*}{7.} & \multirow{4}{*}{$\begin{array}{l}\tau \alpha \mu \pi \rho \alpha \tau \sigma \alpha ́ k 1 \alpha \mu \nu \\
\text { 'my floaties' }\end{array}$} & \multirow{2}{*}{ Left } & Future & 0.72 & 1799 \\
\hline & & & Past & 0.78 & 2039 \\
\hline & & \multirow{2}{*}{ Right } & Future & 0.78 & 1775 \\
\hline & & & Past & 0.78 & 1806 \\
\hline \multirow{4}{*}{8.} & \multirow{4}{*}{ 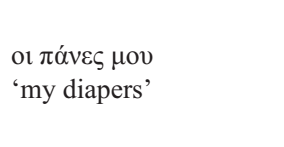 } & \multirow{2}{*}{ Left } & Future & 0.85 & 1562 \\
\hline & & & Past & 0.93 & 1642 \\
\hline & & \multirow{2}{*}{ Right } & Future & 0.88 & 1446 \\
\hline & & & Past & 0.88 & 1448 \\
\hline \multirow{4}{*}{9.} & \multirow{4}{*}{ 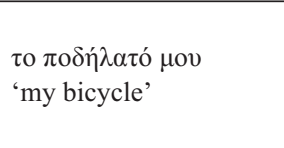 } & \multirow{2}{*}{ Left } & Future & 0.79 & 1407 \\
\hline & & & Past & 0.88 & 1515 \\
\hline & & \multirow{2}{*}{ Right } & Future & 0.85 & 1341 \\
\hline & & & Past & 0.88 & 1428 \\
\hline \multirow{4}{*}{10.} & \multirow{4}{*}{$\begin{array}{l}\text { ol } \kappa \alpha \sigma \varepsilon ́ \tau \varepsilon \varsigma \mu \mathrm{ov} \\
\text { 'my cassettes' }\end{array}$} & \multirow{2}{*}{ Left } & Future & 0.67 & 2224 \\
\hline & & & Past & 0.80 & 2201 \\
\hline & & & Future & 0.90 & 1928 \\
\hline & & Right & Past & 0.80 & 1805 \\
\hline & & & Future & 0.82 & 1805 \\
\hline 11 & 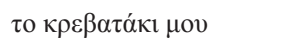 & Left & Past & 0.85 & 1720 \\
\hline 11. & 'my baby bed' & & Future & 0.88 & 1547 \\
\hline & & Right & Past & 0.80 & 1519 \\
\hline & & Ieft & Future & 0.79 & 1815 \\
\hline 12 & 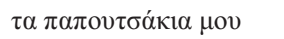 & Left & Past & 0.88 & 1856 \\
\hline 12. & 'my baby shoes' & Dight & Future & 0.88 & 1693 \\
\hline & & Right & Past & 0.90 & 1697 \\
\hline & & I eft & Future & 0.79 & 1674 \\
\hline 13 & 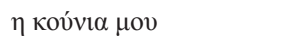 & Left & Past & 0.93 & 1806 \\
\hline 13. & 'my cradle' & Right & Future & 0.88 & 1663 \\
\hline & & Right & Past & 0.83 & 1625 \\
\hline & & Ioff & Future & 0.85 & 1795 \\
\hline 14 & 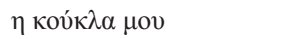 & Left & Past & 0.88 & 1817 \\
\hline 14. & 'my doll' & Pioht & Future & 0.90 & 1656 \\
\hline & & Kignt & Past & 0.88 & 1704 \\
\hline & & Left & Future & 0.62 & 1855 \\
\hline & 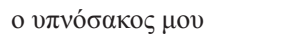 & & Past & 0.75 & 1846 \\
\hline 15 & 'my baby sleeping bag' & Pioht & Future & 0.73 & 1928 \\
\hline & & Right & Past & 0.68 & 2210 \\
\hline & & Left & Future & 0.85 & 1695 \\
\hline & 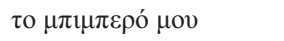 & Left & Past & 0.93 & 1670 \\
\hline 16. & 'my baby bottle' & Dicht & Future & 0.83 & 1759 \\
\hline & & Right & Past & 0.90 & 1683 \\
\hline & & I & Future & 0.79 & 1914 \\
\hline 17 & 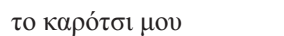 & Left & Past & 0.83 & 1875 \\
\hline $1 \%$ & 'my cart' & Right & Future & 0.85 & 1850 \\
\hline & & Right & Past & 0.88 & 1838 \\
\hline & & & Future & 0.85 & 1850 \\
\hline 18 & 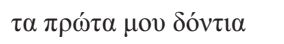 & Left & Past & 0.93 & 1852 \\
\hline 18. & 'my baby teeth' & Pioht & Future & 0.85 & 1834 \\
\hline & & Right & Past & 0.90 & 2041 \\
\hline
\end{tabular}




\begin{tabular}{|c|c|c|c|c|c|}
\hline & ITEM & PAST BUTTON & $\begin{array}{l}\text { EXPERIMENTER } \\
\text { POSITION }\end{array}$ & $\begin{array}{c}\text { MEAN } \\
\text { ACCURACY }\end{array}$ & $\begin{array}{l}\text { MEAN REACTION } \\
\text { TIMES (MS) }\end{array}$ \\
\hline \multirow{4}{*}{19.} & \multirow{4}{*}{$\begin{array}{l}\tau o \mu \pi \alpha \lambda \dot{\varepsilon} \tau o \mu o v \\
\text { "my ballet class' }\end{array}$} & \multirow[b]{2}{*}{ Left } & $\begin{array}{l}\text { POSITION } \\
\text { Future }\end{array}$ & $\begin{array}{c}\text { ACCURACY } \\
0.74\end{array}$ & $\begin{array}{c}1982 \\
1982\end{array}$ \\
\hline & & & Past & 0.78 & 1935 \\
\hline & & \multirow{2}{*}{ Right } & Future & 0.85 & 1769 \\
\hline & & & Past & 0.80 & 1858 \\
\hline \multirow{4}{*}{20.} & \multirow{4}{*}{$\begin{array}{l}\tau o v \eta \pi \imath \alpha \gamma \omega \gamma \varepsilon i ́ o ~ \mu o v \\
\text { 'my kindergarten' }\end{array}$} & \multirow{2}{*}{ Left } & Future & 0.85 & 1625 \\
\hline & & & Past & 0.83 & 1685 \\
\hline & & \multirow{2}{*}{ Right } & Future & 0.88 & 1524 \\
\hline & & & Past & 0.88 & 1633 \\
\hline
\end{tabular}

TABle A5. Past items.

\begin{tabular}{|c|c|c|c|c|c|}
\hline & ITEM & $\begin{array}{l}\text { PAST BUTTON } \\
\text { POSITION }\end{array}$ & $\begin{array}{l}\text { EXPERIMENTER } \\
\text { POSITION }\end{array}$ & $\begin{array}{c}\text { MEAN } \\
\text { ACCURACY }\end{array}$ & $\begin{array}{l}\text { MEAN REACTION } \\
\text { TIMES (MS) }\end{array}$ \\
\hline \multirow{4}{*}{1.} & \multirow{4}{*}{$\begin{array}{l}\text { o } \alpha \rho \rho \alpha \beta \omega ́ v \alpha \varsigma \mu \mathrm{ov} \\
\text { 'my engagement party' }\end{array}$} & \multirow{2}{*}{ Left } & Future & 0.87 & 1892 \\
\hline & & & Past & 0.85 & 1802 \\
\hline & & \multirow{2}{*}{ Right } & Future & 0.85 & 1664 \\
\hline & & & Past & 0.85 & 1659 \\
\hline \multirow{4}{*}{2.} & \multirow{4}{*}{$\begin{array}{l}\eta \kappa \eta \delta \varepsilon i ́ \alpha \mu \text { ov } \\
\text { 'my funeral' }\end{array}$} & \multirow{2}{*}{ Left } & Future & 0.87 & 1813 \\
\hline & & & Past & 0.88 & 1661 \\
\hline & & \multirow{2}{*}{ Right } & Future & 0.93 & 1560 \\
\hline & & & Past & 0.88 & 1562 \\
\hline \multirow{4}{*}{3.} & \multirow{4}{*}{ 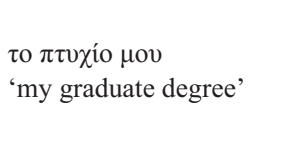 } & \multirow{2}{*}{ Left } & Future & 0.85 & 1760 \\
\hline & & & Past & 0.93 & 1794 \\
\hline & & \multirow{2}{*}{ Right } & Future & 0.90 & 1667 \\
\hline & & & Past & 0.85 & 1699 \\
\hline \multirow{4}{*}{4.} & \multirow{4}{*}{ 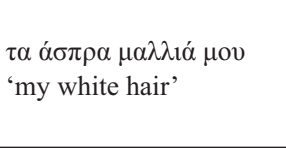 } & \multirow{2}{*}{ Left } & Future & 0.85 & 1972 \\
\hline & & & Past & 0.85 & 1946 \\
\hline & & \multirow{2}{*}{ Right } & Future & 0.83 & 1675 \\
\hline & & & Past & 0.83 & 1770 \\
\hline \multirow{4}{*}{5.} & \multirow{4}{*}{$\begin{array}{l}\mathrm{A} \lambda \tau \sigma \chi \alpha \dot{\alpha} \mu \varepsilon \rho \\
\text { 'Alzheimer's' }\end{array}$} & \multirow{2}{*}{ Left } & Future & 0.89 & 1492 \\
\hline & & & Past & 0.90 & 1343 \\
\hline & & \multirow{2}{*}{ Right } & Future & 0.90 & 1587 \\
\hline & & & Past & 0.88 & 1413 \\
\hline \multirow{4}{*}{6.} & \multirow{4}{*}{$\begin{array}{l}\text { ot } \rho v \tau i ́ \delta \varepsilon \varsigma \\
\text { 'the wrinkles' }\end{array}$} & \multirow{2}{*}{ Left } & Future & 0.79 & 2003 \\
\hline & & & Past & 0.90 & 1790 \\
\hline & & \multirow{2}{*}{ Right } & Future & 0.83 & 1674 \\
\hline & & & Past & 0.80 & 1654 \\
\hline \multirow{4}{*}{7.} & \multirow{4}{*}{$\begin{array}{l}\eta \mu \alpha \sigma \varepsilon ́ \lambda \alpha \mu \text { ov } \\
\text { 'my denture' }\end{array}$} & & Future & 0.77 & 1891 \\
\hline & & Lent & Past & 0.83 & 1940 \\
\hline & & & Future & 0.60 & 1588 \\
\hline & & Kignt & Past & 0.70 & 1774 \\
\hline & & & Future & 0.85 & 1844 \\
\hline & 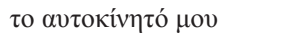 & Lent & Past & 0.93 & 1760 \\
\hline 8. & 'my car' & Right & Future & 0.90 & 1706 \\
\hline & & Kigmt & Past & 0.88 & 1684 \\
\hline & & Left & Future & 0.87 & 2077 \\
\hline 9 & 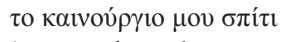 & Leit & Past & 0.90 & 2056 \\
\hline 9. & 'my new house' & Right & Future & 0.88 & 1936 \\
\hline & & Kignt & Past & 0.88 & 2007 \\
\hline & & Left & Future & 0.79 & 2227 \\
\hline 10 & 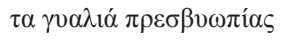 & Lent & Past & 0.85 & 2362 \\
\hline 10. & 'glasses' & Right & Future & 0.88 & 2027 \\
\hline & & IIgmt & Past & 0.90 & 1995 \\
\hline
\end{tabular}




\begin{tabular}{|c|c|c|c|c|c|}
\hline & ITEM & $\begin{array}{l}\text { PAST BUTTON } \\
\text { POSITION }\end{array}$ & $\begin{array}{c}\text { EXPERIMENTER } \\
\text { POSITION }\end{array}$ & $\begin{array}{c}\text { MEAN } \\
\text { ACCURACY }\end{array}$ & $\begin{array}{l}\text { MEAN REACTION } \\
\text { TIMES (MS) }\end{array}$ \\
\hline \multirow{4}{*}{11.} & \multirow{4}{*}{$\begin{array}{l}\text { o } \sigma 0 ́ \zeta v \gamma o ́ \varsigma \mu \text { ov } \\
\text { 'my husband' }\end{array}$} & \multirow{2}{*}{ Left } & Future & 0.89 & 1943 \\
\hline & & & Past & 0.90 & 1666 \\
\hline & & \multirow{2}{*}{ Right } & Future & 0.88 & 1706 \\
\hline & & & Past & 0.83 & 1587 \\
\hline \multirow{4}{*}{12.} & \multirow{4}{*}{$\begin{array}{l}\tau \alpha \pi \alpha \mathrm{i} \delta \text { i } \alpha \text { ov } \\
\text { 'my children' }\end{array}$} & \multirow{2}{*}{ Left } & Future & 0.87 & 1596 \\
\hline & & & Past & 0.90 & 1627 \\
\hline & & \multirow{2}{*}{ Right } & Future & 0.85 & 1571 \\
\hline & & & Past & 0.80 & 1567 \\
\hline \multirow{4}{*}{13.} & \multirow{4}{*}{ 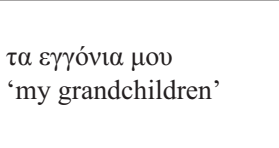 } & \multirow{2}{*}{ Left } & Future & 0.85 & 1737 \\
\hline & & & Past & 0.90 & 1628 \\
\hline & & \multirow{2}{*}{ Right } & Future & 0.85 & 1688 \\
\hline & & & Past & 0.83 & 1497 \\
\hline \multirow{4}{*}{14.} & \multirow{4}{*}{$\begin{array}{l}\text { o } \gamma \alpha \dot{\alpha} \mu \mathrm{o}_{\mu} \mu \mathrm{ov} \\
\text { 'my wedding', }\end{array}$} & \multirow{2}{*}{ Left } & Future & 0.89 & 1584 \\
\hline & & & Past & 0.90 & 1741 \\
\hline & & \multirow{2}{*}{ Right } & Future & 0.90 & 1621 \\
\hline & & & Past & 0.88 & 1511 \\
\hline \multirow{4}{*}{15.} & \multirow{4}{*}{ 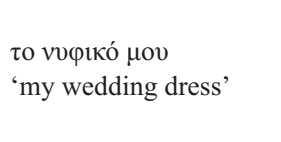 } & \multirow{2}{*}{ Left } & Future & 0.87 & 1667 \\
\hline & & & Past & 0.93 & 1616 \\
\hline & & \multirow{2}{*}{ Right } & Future & 0.88 & 1539 \\
\hline & & & Past & 0.88 & 1481 \\
\hline \multirow{4}{*}{16.} & \multirow{4}{*}{$\begin{array}{l}\text { o } \alpha \rho \rho \alpha \beta \omega v ı \alpha \sigma \tau \text { 'ó } \varsigma \mu v \\
\text { 'my fiancé' }\end{array}$} & \multirow{2}{*}{ Left } & Future & 0.82 & 1890 \\
\hline & & & Past & 0.88 & 1802 \\
\hline & & \multirow{2}{*}{ Right } & Future & 0.88 & 1650 \\
\hline & & & Past & 0.88 & 1692 \\
\hline \multirow{4}{*}{17.} & \multirow{4}{*}{$\begin{array}{l}\eta \beta \varepsilon ́ \rho \alpha \mu \text { ov } \\
\text { 'my wedding ring' }\end{array}$} & Left & Future & 0.87 & 1564 \\
\hline & & Left & Past & 0.90 & 1614 \\
\hline & & Right & Future & 0.85 & 1480 \\
\hline & & Kignt & Past & 0.90 & 1434 \\
\hline & & Left & Future & 0.89 & 2046 \\
\hline & 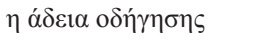 & Lent & Past & 0.93 & 2139 \\
\hline 18. & 'my driving license' & Right & Future & 0.88 & 1898 \\
\hline & & Right & Past & 0.88 & 1899 \\
\hline & & Left & Future & 0.89 & 1601 \\
\hline 19 & o $\mu \mathrm{r} \sigma \theta$ ó $\varsigma \mu \mathrm{ov}$ & & Past & 0.93 & 1680 \\
\hline & 'my salary' & Rioht & Future & 0.90 & 1562 \\
\hline & & Kignt & Past & 0.88 & 1631 \\
\hline & & & Future & 0.87 & 1559 \\
\hline 20 & 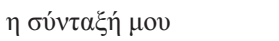 & Left & Past & 0.93 & 1515 \\
\hline 20. & 'my pension' & Rioh & Future & 0.88 & 1516 \\
\hline & & Kignt & Past & 0.90 & 1627 \\
\hline
\end{tabular}

TABLE A6. Future items.

\section{REFERENCES}

Adamou, Evangelia. 2011. Temporal uses of definite articles and demonstratives in Pomak (Slavic, Greece). Lingua 121.871-89. DOI: 10.1016/j.lingua.2010.12.001.

Adamou, Evangelia. 2013. Change and variation in a trilingual setting: Evidentiality in Pomak (Slavic, Greece). The interplay of variation and change in contact settings: Morphosyntactic studies, ed. by Isabelle Léglise and Claudine Chamoreau, 229-52. Amsterdam: John Benjamins.

Agresti, Alan. 2010. Analysis of ordinal categorical data. 2nd edn. (Wiley series in probability and statistics.) Hoboken, NJ: Wiley.

Aikhenvald, Alexandra Y. 2003. A grammar of Tariana, from Northwest Amazonia. Cambridge: Cambridge University Press. 
Anderson, Stephen R., and Edward L. Keenan. 1985. Deixis. Language, typology and syntactic description, ed. by Timothy Shopen, 259-308. Cambridge: Cambridge University Press.

AristotLe. 1926. On interpretation. Trans. by E. M. Edghill. The works of Aristotle, vol. 2, ed. by W. D. Ross. Oxford: Clarendon.

BorODITSKY, LERA. 2000. Metaphoric structuring: Understanding time through spatial metaphors. Cognition 75.1-28. DOI: 10.1016/S0010-0277(99)00073-6.

Bueti, Domenica, and Vincent Walsh. 2009. The parietal cortex and the representation of time, space, number and other magnitudes. Philosophical Transactions of the Royal Society B: Biological Sciences 364.1831-40. DOI: 10.1098/rstb.2009.0028.

Bürkner, PAul-Christian. 2017. brms: An R package for Bayesian multilevel models using Stan. Journal of Statistical Software 80.1-28. DOI: 10.18637/jss.v080.i01.

Bürkner, Paul-Christian. 2018. Advanced Bayesian multilevel modeling with the $\mathrm{R}$ package brms. The R Journal 10.395-411. DOI: 10.32614/RJ-2018-017.

Bybee, Joan; Revere Perkins; and William Pagliuca. 1994. The evolution of grammar: Tense, aspect, and modality in the languages of the world. Chicago: University of Chicago Press.

Bylund, Emanuel, and Panos Athanasopoulos. 2017. The Whorfian time warp: Representing duration through the language hourglass. Journal of Experimental Psychology: General 146.911-16. DOI: 10.1037/xge0000314.

Casasanto, Daniel, and Lera Boroditsky. 2008. Time in the mind: Using space to think about time. Cognition 106.579-93. DOI: 10.1016/j.cognition.2007.03.004.

Casasanto, Daniel, and Roberto Bottini. 2014. Mirror reading can reverse the flow of time. Journal of Experimental Psychology: General 143.473-79. DOI: 10.1037/a0033 297.

Christensen, Rune H. B., and Peer Bruun Brockhoff. 2013. Analysis of sensory ratings data with cumulative link models. Journal de la Société Française de Statistique and Revue de Statistique Appliquée 154.58-79.

de la Fuente, Juanma; Julio Santiago; Antonio Román; Cristina Dumitrache; and Daniel Casasanto. 2014. When you think about it, your past is in front of you: How culture shapes spatial conceptions of time. Psychological Science 25.1682-90. DOI: $10.1177 / 0956797614534695$.

Dehaene, Stanislas; Serge Bossini; and Pascal Giraux. 1993. The mental representation of parity and number magnitude. Journal of Experimental Psychology: General 123.371-96. DOI: 10.1037/0096-3445.122.3.371.

EnÇ, Mürvet. 1986. Towards a referential analysis of temporal expressions. Linguistics and Philosophy 9.405-26. DOI: 10.1007/BF00603217.

Fanciullo, Davide. 2019. Temporal expressions in nominals: Tripartite deictics in the Rhodope dialects of Bulgaria. Berlin: Peter Lang. DOI: 10.3726/b15767.

Fuhrman, Orly, and Lera Boroditsky. 2010. Cross-cultural differences in mental representations of time: Evidence from an implicit nonlinguistic task. Cognitive Science 34.1430-51. DOI: 10.1111/j.1551-6709.2010.01105.x.

Gelman, Andrew; John B. Carlin; Hal S. Stern; David B. Dunson; Aki Vehtari; and Donald B. Rubin. 2014. Bayesian data analysis. 3rd edn. Boca Raton, FL: CRC Press.

Gibson, Edward; Steven T. Piantadosi; and Evelina Fedorenko. 2013. Quantitative methods in syntax/semantics research: A response to Sprouse and Almeida (2013). Language and Cognitive Processes 28.229-40. DOI: 10.1080/01690965.2012.704385.

Gundel, Jeanette K.; Nancy Hedberg; and Ron Zacharski. 1993. Cognitive status and the form of referring expressions. Language 69.274-307. DOI: 10.2307/416535.

Hoekstra, Rink; Richard D. Morey; JefFrey N. Rouder; and Eric-Jan Wagenmakers. 2014. Robust misinterpretation of confidence intervals. Psychonomic Bulletin \& Review 21.1157-64. DOI: 10.3758/s13423-013-0572-3.

Hüttermann, Stefanie, and Daniel Memmert. 2017. The attention window: A narrative review of limitations and opportunities influencing the focus of attention. Research Quarterly for Exercise and Sport 88.169-83. DOI: 10.1080/02701367.2017.1293228.

Hüttermann, Stefanie; Benjamin Nö̈l; and Daniel Memmert. 2017. Evaluating erroneous offside calls in soccer. PLOS ONE 12(3):e0174358. DOI: 10.1371/journal.pone .0174358 . 
Kanevska-Nikolova, Elena. 2006. Trojnoto členuvane v rodopskite govori. Plovdiv: Univ. Izdatelstvo Paisij Xilendarski.

Kong, Feng, and XuQun You. 2012. Space-time compatibility effects in the auditory modality. Experimental Psychology 59.82-87. DOI: 10.1027/1618-3169/a000129.

KruschKe, John K. 2013. Bayesian estimation supersedes the $t$ test. Journal of Experimental Psychology: General 142.573-603. DOI: 10.1037/a0029146.

Kruschke, John K. 2015. Doing Bayesian data analysis: A tutorial with R, JAGS, and Stan. 2nd edn. London: Academic Press.

KruschKe, John K., and Torrin M. Liddell. 2018. The Bayesian new statistics: Hypothesis testing, estimation, meta-analysis, and power analysis from a Bayesian perspective. Psychonomic Bulletin \& Review 25.178-206. DOI: 10.3758/s13423-016-1221-4.

LeCARME, JACQUeline. 1999. Nominal tense and tense theory. Empirical issues in formal syntax and semantics 2: Selected papers from the Colloque de syntaxe et sémantique à Paris (CSSP 1997), ed. by Francis Corblin, Carmen Dobrovie-Sorin, and Jean-Marie Marandin, 333-54. The Hague: Holland Academic Graphics.

LeCARMe, JACQUeline. 2004. Tense in nominals. The syntax of time, ed. by Jacqueline Guéron and Jacqueline Lecarme, 440-75. Cambridge, MA: MIT Press.

LECARME, JACQUELINE. 2012. Nominal tense. The Oxford handbook of tense and aspect, ed. by Robert I. Binnick, 696-718. Oxford: Oxford University Press.

Lewandowski, Daniel; Dorota Kurowicka; and Harry Joe. 2009. Generating random correlation matrices based on vines and extended onion method. Journal of Multivariate Analysis 100.1989-2001. DOI: 10.1016/j.jmva.2009.04.008.

Lupyan, Gary, and Andy Clark. 2015. Words and the world: Predictive coding and the language-perception-cognition interface. Current Directions in Psychological Science 24.279-84. DOI: 10.1177/0963721415570732.

Lyons, John. 1977. Semantics. Cambridge: Cambridge University Press.

Mathot, Sebastiaan; Daniel Schreis; and Jan Theeuwes. 2012. OpenSesame: An open-source, graphical experiment builder for the social sciences. Behavior Research Methods 44.314-24. DOI: 10.3758/s13428-011-0168-7.

Matthewson, Lisa. 2005. On the absence of tense on determiners. Lingua 115.1697-1735. DOI: 10.1016/j.lingua.2004.08.001.

McCullagh, Peter. 1980. Regression models for ordinal data. Journal of the Royal Statistical Society: Series B (Methodological) 42.109-27. DOI: 10.1111/j.2517-6161.1980 .tb01109.x.

McElreath, Richard. 2016. Statistical rethinking: A Bayesian course with examples in $R$ and Stan. Boca Raton, FL: CRC Press.

Morey, Richard D.; Rink Hoekstra; Jeffrey N. Rouder; Michael D. Lee; and EriCJAN WAGENMAKERS. 2016. The fallacy of placing confidence in confidence intervals. Psychonomic Bulletin \& Review 23.103-23. DOI: 10.3758/s13423-015-0947-8.

Musan, Renate. 1999. Temporal interpretation and information-status of noun phrases. Linguistics and Philosophy 22.621-61. Online: https://www.jstor.org/stable/25001763.

Nicenboim, Bruno, and Shravan Vasishth. 2016. Statistical methods for linguistic research: Foundational ideas-Part II. Language and Linguistics Compass 10.591-613. DOI: $10.1111 / \operatorname{lnc} 3.12207$.

Nicenboim, Bruno; Shravan Vasishth; Felix Engelmann; and Katja Suckow. 2018. Exploratory and confirmatory analyses in sentence processing: A case study of number interference in German. Cognitive Science 42.1075-1100. DOI: 10.1111/cogs.12589.

Nordlinger, Rachel, and Louise SAdLer. 2004. Nominal tense in a crosslinguistic perspective. Language 80.776-806. DOI: 10.1353/lan.2004.0219.

NordLINGer, RACHEL, and LOUISE SADLER. 2008. When is a temporal marker not a tense? Reply to Tonhauser (2007). Language 84.325-31. DOI: 10.1353/lan.0.0013.

NúÑEz, RAFAel, and Kensy CoOPERRIDER. 2013. The tangle of space and time in human cognition. Trends in Cognitive Sciences 17.220-29. DOI: 10.1016/j.tics.2013.03.008.

Ouellet, Marc; Julio Santiago; Maria Jesus Funes; and Juan Lupiáñez. 2010. Thinking about the future moves attention to the right. Journal of Experimental Psychology: Human Perception and Performance 36.17-24. DOI: 10.1037/a0017176.

R Core Team. 2018. R: A language and environment for statistical computing. Vienna: R Foundation for Statistical Computing. Online: https://www.R-project.org/. 
Sorensen, Tanner; Sven Hohenstein; and Shravan Vasishth. 2016. Bayesian linear mixed models using Stan: A tutorial for psychologists, linguists and cognitive scientists. The Quantitative Methods for Psychology 12.175-200. DOI: 10.20982/tqmp.12.3 .p175.

Tonhauser, Judith. 2007. Nominal tense? The meaning of Guaraní nominal temporal markers. Language 83.831-69. DOI: 10.1353/lan.2008.0037.

TONHAUSER, JUDiTh. 2008. Defining crosslinguistic categories: The case of nominal tense (Reply to Nordlinger and Sadler). Language 84.332-42. DOI: 10.1353/lan.0.0017.

Torralbo, Ana; Julio Santiago; and Juan Lupiáñez. 2006. Flexible conceptual projection of time onto spatial frames of reference. Cognitive Science 30.745-57. DOI: $10.1207 / \mathrm{s} 15516709 \operatorname{cog} 000067$.

Traugott, Elizabeth Closs. 1978. On the expression of spatio-temporal relations in language. Universals of human language, vol. 3: Word structure, ed. by Joseph H. Greenberg, Charles A. Ferguson, and Edith A. Moravcsik, 369-400. Stanford, CA: Stanford University Press.

Tversky, Barbara; Sol Kugelmass; and Atalia Winter. 1991. Cross-cultural and developmental trends in graphic productions. Cognitive Psychology 23.515-57. DOI: 10.1016/0010-0285(91)90005-9.

Ulrich, Rolf, and Claudia Maienborn. 2010. Left-right coding of past and future in language: The mental timeline during sentence processing. Cognition 117.126-38. DOI: 10.1016/j.cognition.2010.08.001.

Vasishth, Shravan, and Bruno Nicenboim. 2016. Statistical methods for linguistic research: Foundational ideas-Part I. Language and Linguistics Compass 10.349-69. DOI: $10.1111 / \operatorname{lnc} 3.12201$.

Vikner, Carl, and Per Anker Jensen. 2002. A semantic analysis of the English genitive: Interaction of lexical and formal semantics. Studia Linguistica 56.191-226. DOI: 10 $.1111 / 1467-9582.00092$.

WAGENMAKERS, ERIC-JAN. 2007. A practical solution to the pervasive problems of $p$ values. Psychonomic Bulletin \& Review 14.779-804. DOI: 10.3758/BF03194105.

Walker, Esther J.; Benjamin K. Bergen; and Rafael NúÑEz. 2017. The spatial alignment of time: Differences in alignment of deictic and sequence time along the sagittal and lateral axes. Acta Psychologica 175.13-20. DOI: 10.1016/j.actpsy.2017.02.001.

Weger, Ulrich W., and JAY Pratt. 2008. Time flies like an arrow: Space-time compatibility effects suggest the use of a mental timeline. Psychonomic Bulletin \& Review 15. 426-30. DOI: 10.3758/PBR.15.2.426.

WiltschKo, Martina. 2003. On the interpretability of tense on D and its consequences for case theory. Lingua 113.659-96. DOI: 10.1016/S0024-3841(02)00116-X.

ZeBian, SAMAR. 2005. Linkages between number concepts, spatial thinking, and directionality of writing: The SNARC effect and the reverse SNARC effect in English and Arabic monoliterates, biliterates, and illiterate Arabic speakers. Journal of Cognition and Culture 5.165-90. DOI: 10.1163/1568537054068660.

[evangelia.adamou@cnrs.fr] (Adamou)

[yairhen@gmail.com] (Haendler)
[Received 25 February 2019; revision invited 29 May 2019; revision received 25 September 2019; revision invited 1 January 2020; revision received 6 January 2020; accepted pending revisions 2 March 2020; revision received 3 March 2020; accepted 13 March 2020] 